Revue d'histoire de l'enfance « irrégulière »

Le Temps de l'histoire

Hors-série | 2007

Pages d'histoire, la protection judiciaire des mineurs, $\mathrm{XIX} \mathrm{X}^{\mathrm{e}} \mathrm{XX} \mathrm{X}^{\mathrm{e}}$ siècles

\title{
Sur les traces des premiers éducateurs de l'Éducation surveillée, 1937-1962
}

Jacques Bourquin

\section{(2) OpenEdition \\ Journals}

Édition électronique

URL : http://journals.openedition.org/rhei/3008

DOI : 10.4000/rhei.3008

ISBN : 978-2-7535-1647-2

ISSN : $1777-540 \mathrm{X}$

Éditeur

Presses universitaires de Rennes

Édition imprimée

Date de publication : 1 juin 2007

Pagination : 17-95

ISSN : $1287-2431$

Référence électronique

Jacques Bourquin, «Sur les traces des premiers éducateurs de l'Éducation surveillée, 1937-1962 », Revue d'histoire de l'enfance « irrégulière » [En ligne], Hors-série | 2007, mis en ligne le 01 février 2010, consulté le 30 avril 2019. URL : http://journals.openedition.org/rhei/3008; DOI : 10.4000/rhei.3008 


\section{Sur les traces des premiers éducateurs de l'Éducation surveillée 1937-1962}

\section{Introduction}

Un long XIXème siècle. Des mineurs de justice sous la férule des gardiens et des surveillants

Les gardiens

- Une exception toutefois : la colonie de Mettray

Où l'on commence à parler d'éducateurs. Les débats au début du XXème siècle

Des velléités de réforme, le surveillant devient moniteur 1934-1937, les campagnes de presse contre les bagnes d'enfants. L'apparition des moniteurs-éducateurs

- Les campagnes de presse

- L’apparition des moniteurs-éducateurs

Vers la professionnalisation des éducateurs

1937-1939 : Le temps des réformes, la génération des pionniers

- Le début des réformes

- Hourcq, Courtois, Dhallenne : les réformateurs de Saint-Maurice et Saint-Hilaire

- Quelques éléments sur les moniteurs-éducateurs de cette époque 1942-1945 : la génération des moniteurs-éducateurs de la guerre

- Les premiers éducateurs du secteur privé

- Les moniteurs-éducateurs de l'Éducation surveillée

- Les monitrices-éducatrices et les établissements de filles 
- Un essai de formation des moniteurs-éducateurs. La session

Lagache à Clermont-Ferrand, novembre 1943

Les moniteurs-éducateurs qui sont restés après la guerre

\section{L'éducateur de l'Éducation surveillée}

\section{5-1952 : une première génération}

- Le décret 10 avril 1945 : le statut

- Construire l'Éducation surveillée et l'éducateur

- Éléments personnels concernant les éducateurs du statut de 1945

- L'univers de l'éducateur en 1945-1950

- La professionnalisation en cours

1952-1962 : la génération des "vaucressonniens"

- Le centre de formation et d'études

- Le projet de formation initiale

- L'atmosphère de Vaucresson

- Regard porté sur "les vaucressoniens"

\section{Pour conclure}




\section{Introduction}

Éducateur à l'Éducation surveillée à partir de 1959, puis longtemps formateur avant d'occuper des fonctions qui m'amenèrent à faire de la recherche historique, je m'étais très vite interrogé, avec quelques jeunes collègues, sur les origines de l'Éducation surveillée et sur les premiers personnels. J'avais eu à les côtoyer, lors de mes premières années de pratique éducative, j’avais partagé leur quotidien avec des jeunes... Lorsque mon intérêt se focalisait plus sur leur histoire dans l'institution, ils me laissaient entendre qu'il n'y avait pas grand chose à en dire, les temps étaient révolus, la réforme s'était faite, ils en avaient été les acteurs au quotidien. Y avait-il tant de choses à dire ?

J'avais l'impression que cette histoire au jour le jour de l'Éducation surveillée s'était construite plus ou moins sur du sable où la mémoire s'enfouissait. Cette mémoire survivait dans quelques articles jaunis de la Revue de l'Éducation surveillée et de Rééducation dont les auteurs avaient voulu expliquer ce qu'ils essayaient de faire, de construire avec les jeunes, dès le lendemain de la guerre, puis les témoignages avaient disparu.

L'impression qui ressortait était que cette mémoire n'appartenait encore à aucune histoire, elle ne pouvait s'intéresser qu'à des évènements de premier plan, spectaculaires, " historiques ", et pas à un quotidien, celui-ci restait dans le domaine du privé, au risque de s'occulter.

Dans le cadre d'une recherche historique élaborée au CEFRES de Vaucresson, en 1980, sur le thème de "la naissance de l'Éducation surveillée ", avec quelques autres historiens, sociologues, psychologues, j’avais proposé d'apporter ma contribution à ce travail par une restitution de la parole de ces pionniers, de ces premiers éducateurs de l'Éducation surveillée, à partir d'entretiens et d'un travail sur archives. Ce fut l'objet d'une publication dans Les Cahiers du CRIV, en 1986.

Puis j'ai poursuivi ce travail en l'étendant jusqu'à 1962, une période charnière pour l'Éducation surveillée puisqu'elle correspond à la fois aux premières applications de l'ordonnance du 23 décembre 1958 sur l'enfance en danger, qui fait entrer l'Éducation surveillée dans le champ de la prévention, et à son inscription au IVème Plan, en 1962, qui va lui permettre en quelques années de considérablement élargir son activité.

Autant le rôle des décideurs peut apparaître clair et repérable dans les 
divers découpages institutionnels et historiques, ils ont écrit, ils ont pesé de leur poids sur les décisions, autant celui des acteurs est plus difficile à saisir, il échappe aux diverses chronologies, nous sommes de surcroît dans le champ de la pratique professionnelle, un domaine où la part de l'empirisme est dominante, où le directeur est intimement lié à l'institution qu'il dirige jusqu'à s'identifier à elle, où chaque établissement, quelles que soient les orientations politiques ou le discours théorique, a sa dynamique propre.

L'incursion progressive dans cet univers des éducateurs n'aboutit que très lentement à l'idée de professionnalisation. Il s'agit dans un premier temps de situer des personnes qui en des lieux déterminés ont contribué à "faire " l'Éducation surveillée, il était nécessaire de mentionner ces premiers acteurs.

Dans le choix de nos entretiens, il nous fallait veiller à rencontrer, d'une part, ceux qui avaient eu des rôles de responsabilité, d'autre part, ceux qui étaient restés dans des positions moins hiérarchiques et chaque jour au contact des jeunes. Ayant été éducateur comme eux, j'étais à la fois très sensible à leur propos, j’avais parfois, dans ma pratique avec les jeunes, ressenti les mêmes choses, mais aussi, soucieux de garder une certaine distance critique par rapport à ceux-ci.

Il me fallait aussi des informations plus objectives, d'où un important travail d'archives et de lectures de rapports d'inspection, que j'ai complété par l'analyse de deux cents dossiers d'admission sur la période 1943-1962. Il s'agissait à la fois de percevoir le climat institutionnel des périodes de référence et de cerner progressivement le profil de l'éducateur de l'Éducation surveillée.

Il m'est assez vite apparu, dès nos premiers travaux avec le groupe de " recherche historique " de Vaucresson, en 1980, qu'il fallait, dans cette démarche, privilégier l'aspect chronologique qui englobait à la fois le découpage historique (Front Populaire, période de Vichy, Libération) et le découpage institutionnel. A la chronologie de l'histoire, à celle des textes, semblent s'articuler puis se superposer les générations successives d'éducateurs. Nous en avons distingué trois :

- les pionniers de 1937-1939, les premiers moniteurs-éducateurs. Ils sont une douzaine, le plus souvent recrutés à Saint-Maurice et Saint-Hilaire, les deux institutions pour lesquelles est prévue une réforme suite aux campagnes de presse contre les bagnes d'enfants. 
- les moniteurs-éducateurs de la guerre, 1942-1945. L'Éducation surveillée qui dépend toujours de l'Administration pénitentiaire, suite à des textes de 1942 (circulaire contre la détention provisoire des mineurs, loi du 27 juillet 1942 sur l'enfance délinquante) recrute quelques dizaines de moniteurs-éducateurs dans les centres d'accueil de la région parisienne, à Saint-Maurice, à Saint-Hilaire et dans un établissement acquis en 1943, Saint-Jodard.

- les éducateurs de l'Éducation surveillée, 1945-1962, suite aux statuts du 10 avril 1945 et du 23 avril 1956. Nous distinguerons dans cette génération, qui correspond à l'ordonnance du 2 février 1945 relative à l'enfance délinquante et à la création le 1er septembre 1945 de la direction de l'Éducation surveillée, deux périodes :

-1945-1952, le corps des éducateurs de l'Éducation surveillée se constitue à partir du recrutement sur titre (statut du 10 avril 1945), du détachement de l'Éducation nationale et d'une commission de sélection de l'Administration pénitentiaire. Ils sont quelques centaines ;

- 1952-1962, la mise en place du concours prévu par les statuts du 10 avril 1945 , l'ouverture du centre de formation et d'études de l'Éducation surveillée à Vaucresson (1952), les premières promotions formées à Vaucresson, "les vaucressoniens" (1952-1962), environ deux cents élèves.

Toute cette histoire prend sa source au XIXème siècle, aussi nous est-il paru essentiel d'introduire ce travail par une évocation de ceux qui avaient précédé les éducateurs dans les colonies agricoles et pénitentiaires (les chefs de famille de Mettray, les gardiens, les surveillants...).

\section{Un long XIXème siècle. Des mineurs de justice sous la férule des gar- diens et des surveillants \\ Les gardiens}

La loi pénale de 1791 sur les mineurs consacrait la minorité pénale à 16 ans et la notion de peine éducative, elle prévoyait la création de maisons d'éducation spéciale pour les mineurs considérés comme non-discernants, qui devaient être acquittés, remis à leur famille ou placés dans ces maisons d'éducation spéciale pour y être détenus et élevés jusqu’à leur majorité pénale ou civile. Les mineurs discernants, considérés comme responsables, étaient envoyés en prison pour des peines inférieures de moitié à celles des adultes. 
(1) Fondation d'une colonie agricole de jeunes détenus, Mettray, Paris, Duprat, 1839, p. 5.

(2) Assemblée générale des fondateurs, 1844 .
Les premières maisons d'éducation spéciale n'apparurent que cinquante ans plus tard. En attendant, discernants et non-discernants, non remis à leur famille, subirent le même sort dans les maisons de détention, le plus souvent mêlés avec des adultes. Un système où le non-discernant placé jusqu'à sa majorité subissait une détention bien plus longue que l'enfant considéré comme responsable. Il y avait une confusion totale entre éducation et détention, malgré les textes de loi.

C'est en 1836 qu'est créée la maison d'éducation correctionnelle de la Petite Roquette, à Paris, pour les mineurs non-discernants. Si le souci d'éducation scolaire, religieuse, d'apprentissage figure dans le projet, le personnel est quasi uniquement un personnel de gardiens à l'exception d'un aumônier et d'un instituteur. La Petite Roquette évoluera très vite, pour des raisons disciplinaires, vers un régime d'encellulement intégral.

Un autre modèle, quasi-contemporain, celui des colonies agricoles, se met en place autour de 1840, là encore on ne retrouvera qu'un personnel de gardien.

\section{Une exception toutefois : la colonie de Mettray}

Cette institution, ouverte en 1839 près de Tours, par un magistrat, FrédéricAuguste Demetz, présente la caractéristique de réfuter l'emploi de gardiens. Demetz, qui en a vu le modèle lors d'un voyage en Prusse, parle de chef de famille. Son projet repose sur la nécessité qu’il y a, pour les enfants confiés par le tribunal, " de les éloigner des villes, porteuses de corruption en favorisant leur retour vers le monde rural $"{ }^{(1)}$ mais aussi de constituer auprès du jeune colon une nouvelle famille, sous l'autorité d'un chef de famille qu'il choisissait parmi des jeunes gens de bonne moralité, proposés, le plus souvent, par les curés des paroisses environnantes. Malheureusement, pour des raisons d'ordre budgétaire, les familles regroupant quarante colons ressembleront vite à des escouades militaires d'où une évolution vers un système très disciplinaire.

L'autre innovation de Demetz constituera la création, dès 1839, d'une école des chefs de familles et des contremaîtres qui préfigure, dans une certaine mesure, les premières écoles d'éducateurs qui n'apparaîtront qu'un siècle plus tard. Évoquant les chefs de famille, à peine plus âgés que les colons, c'est la période de l'enseignement mutuel, Demetz mentionnera leur malléabilité à son égard : "Ils se sont identifiés à nos principes, ils se sont fondés sur notre morale. » ${ }^{(2)}$ 
Le véritable chef de famille est Demetz lui-même, une famille qui comptera jusqu'à 700 colons sous le Second Empire, sa dimension éducative aura depuis longtemps laissé la place à un système de plus en plus répressif.

Si Demetz évoquait en 1840 "les innocents coupables ", ${ }^{(3)}$ vingt ans plus tard, on parlera surtout de l'enfant criminel, celui dont les nouvelles théories criminologiques considèreront qu'il porte sa criminalité, sa délinquance dans son patrimoine génétique.

L'heure n'est plus guère à l'éducation mais à des projets fondés uniquement sur la discipline et la sanction.

Les premières colonies publiques apparaissent au milieu du Second Empire : Saint-Hilaire, les Douaires, puis dans les premières années de la IIIème République, Saint-Maurice, Belle-Île, Aniane.

Un directeur de l'Administration pénitentiaire écrira en 1890 : «Si l'enfant continue à fauter, c'est que la discipline n'est pas suffisante. " ${ }^{(4)}$ Les colonies publiques qui se créent entre 1860 et 1890 , soulignent leur aspect répressif et disciplinaire : les jeunes couchent dans des dortoirs grillagés, les cages à poules, à la colonie de Saint-Maurice, les colons construisent leur mur d'enceinte, le travail n'est qu'un élément de la peine. Les colons sont considérés comme inamendables, tout est affaire de surveillance, de sanction et de discipline et cela pendant de longues années jusqu’à leur majorité civile ou pénale.

À Mettray, les chefs de famille sont devenus d'anciens sous-officiers ou d'anciens gardiens de prison en retraite dès la fin du Second Empire.

\section{Où l'on commence à parler d'éducateurs, les débats du début du XXème siècle}

Il faut attendre la fin du XIXème siècle pour que, dans un grand courant porteur des politiques de l'enfance, lui-même lié aux premiers travaux de psychologie de l'enfant, on s'intéresse aux mineurs de justice.

Des comités de défense des enfants traduits en justice se créent en 1890. Composés de magistrats, d'avocats, de médecins, ils critiquent fortement les pratiques et les institutions destinées à ces mineurs.

Une loi du 19 avril 1898 sur « les violences sur et par les enfants ", dont ils sont porteurs, amorce dans une même formulation l'enfant coupable et l'enfant victime. N'y a-t-il pas derrière l'enfant coupable, un enfant victime?
(3) Fondation d'une colonie agricole..., op. cit., p. 17.

(4) Cité par J. Grosmolard, «La lutte contre la criminalité juvénile au XIXème siècle ", in Archives d'anthropologie criminelle, 1907. 
(5) Paul Cuche, Traité de science et de législation pénitentiaires, Paris, Librairie générale de droit et de jurisprudence, 1905.

(6) Henri Joly, A la recherche de l'éducation correctionnelle, Paris, Victor Lecoffre, 1902, p. 60.
Un des membres de ces comités, le pénaliste Paul Cuche, qui a fondé en 1894 la Société dauphinoise des libérés et de sauvetage de l'enfance, insiste, dans son Traité de science et de législation pénitentiaires (1905), sur « la nécessité d'un personnel éducateur nombreux et choisi et la réduction de l'effectif des jeunes dans les colonies pénitentiaires ». Et il ajoute : «sans exiger que chaque enfant ait son ange gardien ». Une vision religieuse de l'éducateur où l'ange côtoie le gardien. Quelques lignes plus loin, de manière plus réaliste, il conclut : "Pour redresser un enfant vicieux, il faut vivre avec lui, il faut que l'éducateur soit un professeur d'école, un contremaître à l'atelier, le compagnon de l'enfant dans les jeux, un conseiller dans les conversations et les heures de liberté... " ${ }^{(5)}$

C'est à la même époque que le journal satirique L'Assiette au beurre dénonce le climat de violence de Mettray ou de la Petite Roquette qui subsiste en tant que maison d'arrêt pour mineurs.

Dans un rapport présenté au Congrès international de criminologie à Bruxelles en 1905, le directeur de l'Administration pénitentiaire, Duflos, fait à plusieurs reprises référence " aux éducateurs ", mais en réalité le terme recouvre surtout l'ensemble des personnels des colonies pénitentiaires et des écoles de réforme, c'est-à-dire un personnel de surveillance. Deux circulaires du 3 mars 1902 et du 25 août 1905 évoquent la nécessité d'une certaine sélection pour les personnels pénitentiaires destinés aux établissements de jeunes détenus.

Dans son ouvrage $\grave{A}$ la recherche de l'éducation correctionnelle, ${ }^{(6)}$ Henri Joly évoque les gardiens qui travaillent dans les institutions de mineurs : "Je les tiens pour de braves gens, de qui on obtient sans trop de peine l'exécution ponctuelle des règlements, ils sont habillés comme des gardiens de prison, ils font partie du même corps, allez donc dire à des enfants qu'ils ne sont pas prisonniers. »

En 1894, on avait substitué au terme de gardien celui de surveillant dans les établissements de mineurs, leur costume était légèrement modifié et à la place du sabre, ils avaient un nerf de bœuf! Il y avait un fossé entre la volonté de réforme et les freins institutionnels.

En 1911, la direction de l'Administration pénitentiaire qui dépendait depuis 1791 du ministère de l'Intérieur, le ministère de la force publique, est rattachée au ministère de la Justice. Un moyen pour la Justice d'influer sur ces établissements qui dépendront d'elle, ce qui était impossible antérieurement du fait de la séparation des pouvoirs. 
Une loi du 22 juillet 1912 crée le tribunal pour enfants et adolescents qui devient, du moins au niveau du principe, un tribunal spécialisé. Pendant de longues années, il n'en existera qu'un seul à Paris ; en province, c'est le tribunal correctionnel qui siègera le jeudi après-midi pour juger les mineurs.

Cette loi fit l'objet de longs travaux préparatoires où le rôle des comités de défense des enfants traduits en justice fut important. La loi votée fut assez décevante, elle maintenait la notion de discernement, continuait à distinguer les mineurs condamnés et les mineurs acquittés, alors que depuis de très longues années, le régime des mineurs acquittés était quasi identique à celui des mineurs condamnés. La voie éducative prévue par la loi de 1850 n'était qu'une illusion, la colonie pénitentiaire n'était en fait qu'une prison.

Seule réforme importante, l'introduction de la mesure de liberté surveillée, de provenance américaine, qui permet au juge d'instruction de maintenir le jeune dans sa famille en attendant qu'il prenne sa décision en évitant l'envoi en établissement correctionnel. Si aux États-Unis et à Saint-Pétersbourg où cette modalité existait, les agents chargés de cette mesure étaient formés et rémunérés, il n'en était pas de même en France.

Ferdinand Dreyfus, un des rapporteurs de la loi de 1912, écrivait : "Les délégués à la surveillance devront être des pédagogues au sens le plus élevé, connaissant l'âme enfantine et les crises qui peuvent l'assaillir, ayant conscience de la tâche morale et éducative qui leur incombe. " ${ }^{(7)}$

Les délégués ne seront pas rémunérés et ne bénéficieront d'aucune formation. Ce sera, en général, des gens œuvrant dans des patronages qui rempliront cette mission.

En France, l'heure n'est pas encore à la professionnalisation de ce que l'on appellera plus tard le travail social. Les activités sociales ne pouvaient relever que de la charité et de la religion. Un magistrat, Léonce André, écrira, en 1914, dans un ouvrage intitulé Les tribunaux pour enfants et la liberté surveillée: "S’il est juste de rémunérer les services rendus, ne faut-il pas craindre d'introduire l'esprit trop souvent indolent et routinier du fonctionnaire, là où il ne doit s'agir que de sacrifice et dévouement ? " ${ }^{(8)}$

La professionnalisation n'était pas à l'ordre du jour. La loi de 1912 n'eut guère d'effets sur les institutions correctives pour mineurs. Au lendemain de la guerre de 1914, on continue à recruter quelques instituteurs chargés de
(7) Ferdinand Dreyfus, Documents parlementaires, Sénat, $n^{\circ} 414,1910$.

(8) Léonce André, Les tribunaux pour enfants et la liberté surveillée, Paris, Éd. Rousseau, 1914, p. 132 sqq. 
(9) Rapport André

Mossé, Inspection générale des services administratifs, 1920, document consulté à la bibliothèque 2RJ, CNFE-PJJ,

Vaucresson.

(10) Rapport Capart, Inspection générale des services administratifs, 1921, document consulté à la bibliothèque $2 \mathrm{RJ}$, CNFE-PJJ, Vaucresson.

(11) Louis Roubaud, Les enfants de Caïn, Paris, Grasset, 1925, p. 214. donner une ou deux heures par jour un enseignement aux colons, ils sont utilisés, le reste du temps, aux services de l'économat. Quant aux surveillants, ils n'auront d'autres missions que des missions disciplinaires.

\section{Des velléités de réforme, le surveillant devient moniteur}

Dans son rapport de l'Inspection générale des services de 1920, André Mossé ${ }^{(9)}$ évoque la nécessité de créer pour les établissements pénitentiaires pour mineurs " un cadre de surveillants, contremaîtres, capables d'être de véritables éducateurs professionnels des pupilles ». Il y a la volonté d'instaurer une véritable formation professionnelle alors que jusque-là, le travail des colons était surtout considéré comme un élément de la peine. On sait que depuis la fin du XIXème siècle, les colons de Saint-Maurice construisaient leur mur d'enceinte, ceux d'Aniane, pendant la guerre de 1914, fournissaient les poilus en godillots.

Le rapport Capart, ${ }^{(10)}$ de 1922 , évoque les colonies privées qui subsistent, en particulier celle de Mettray : "Nonobstant l'appellation de certains surveillants par le nom de chef de famille, l'assimilation avec les colonies publiques est la plus marquée ", ce qui dans l'esprit du rédacteur n'est pas un élément très positif. Un directeur de colonie privée évoque dans le même rapport : "Les surveillants sont autant à surveiller que les pupilles... il y a l'impossibilité de recruter un personnel stable, chez la plupart, il y a un manque manifeste des qualités nécessaires à un éducateur. "

En 1925, un journaliste, Louis Roubaud, sollicite l'Administration pénitentiaire pour visiter quelques établissements pour mineurs. Il publie son enquête Les enfants de Caïn. L'ouvrage a un certain succès. Après avoir visité les colonies d'Eysses, de Belle-Île, d'Aniane, les écoles de préservation pour fille de Clermont de l'Oise et de Doullens, il conclut à la nécessité de fermer ces établissements. "Ces écoles professionnelles qui ne sont en fait que des écoles du bagne, où la férocité des colons n'a d'égale que la dureté du régime disciplinaire... Il faut créer de véritables institutions professionnelles d'où l'instruction secondaire ne sera pas exclue et remplacer les surveillants par des répétiteurs et des chefs d'atelier. " ${ }^{(11)}$

Un rapport de l'Inspection générale des services de 1926, le rapport Breton, conclut à la disparition du terme colonie pénitentiaire. On pouvait le remplacer 
par celui d'école de réforme qui existe déjà pour les plus jeunes ou d'école d'éducation. Concernant les personnels, ils doivent être distincts du personnel pénitentiaire pour adulte, quant au cadre de surveillance il faut lui donner un autre nom et recruter, à la suite d'un examen spécial, de préférence des candidats mariés. L'enseignement professionnel doit être calqué, dans la mesure du possible, sur celui donné par les écoles d'agriculture et d'industrie.

Ce rapport ne sera repris que partiellement par le décret du 31 décembre 1927, sur la création des maisons d'éducation surveillée qui se substituent aux colonies pénitentiaires. Si l'on change le nom des surveillants qui deviennent des moniteurs, si les colons deviennent pupilles, le décret consacre l'uniformité du recrutement et l'interchangeabilité du personnel de l'ensemble des établissements pénitentiaires, majeurs comme mineurs et, sur ce plan, ne suit pas la recommandation du rapport Breton.

Ce décret, que l'on a appelé " réforme sur le papier ", n'apporte concrètement que des changements dérisoires, en devenant moniteur le surveillant remplace son képi par une casquette, et en devenant pupille, le colon abandonne ses sabots pour les remplacer par des galoches!

En fait, la loi de 1912 n'a guère eu d'effet sur l'évolution des institutions pénitentiaires pour mineurs dont les pratiques n'ont pas changé.

L'incurie de l'Administration pénitentiaire, en matière de mineurs, est de plus en plus manifeste dans les années 1920, le gouvernement fait fermer, entre 1920 et 1925, six colonies pénitentiaires (le Val d'Yèvre, les Douaires, Auberive, Saint-Bernard, Gaillon et Haguenau) et les magistrats ordonnent de plus en plus de remises à la famille avec des mesures de liberté surveillée ou des placements dans des sociétés de patronage du secteur privé.

Alors qu'en 1919, 1/5ème des mineurs passés devant les tribunaux pour enfants étaient envoyés en colonie pénitentiaire, soit environ 2000, il n'y en a plus qu'1/10ème en 1927.

Si la loi de 1912 a eu, au lendemain de la guerre, un effet positif, c'est dans le cadre du dépistage et de l'orientation des enfants de justice. En lien avec le courant de la neuropsychiatrie infantile, se créent, à partir de 1923 et dans le cadre du secteur privé, au Service social de l'enfance et au patronage Rollet, les premières consultations concernant les mineurs de justice. Il faudra attendre une dizaine d'années plus tard pour que l'Administration péniten- 
(12) Règlement des maisons d'éducation surveillée, Imprimerie administrative de Melun, 15 février 1930 .

(13) Ibid. tiaire ouvre un centre d'observation au quartier des mineurs de la prison de Fresnes.

Mise en demeure par les pouvoirs publics de construire un véritable projet de réforme, l'Administration pénitentiaire, par un règlement du 15 février 1930, s'efforce de préciser la notion d'éducation surveillée en introduisant dans sa pratique un souci d'observation et un système pédagogique fondé sur la progressivité du comportement du pupille. On définit les fonctions des personnels : les instituteurs sont chargés du redressement moral et de l'éducation scolaire des mineurs mais ils continuent à faire partie d'un corps commun, celui des personnels administratifs et éducatifs, leur avancement passe par les fonctions de greffier comptable, d'économe avant d'accéder aux fonctions de direction. Un instituteur des années 1930 reçoit cette appréciation de son directeur : "Monsieur X. est un bon instituteur, il rend déjà de précieux services à l'économat. " Les moniteurs font toujours partie du cadre de surveillance, placés sous les ordres des maîtres et premiers maîtres. Ils sont " responsables de la garde des enfants qui leur sont confiés, ils veillent à leur bonne tenue, à l'observation des soins de propreté et à l'exécution des tâches imposées, ils interdisent les jeux dangereux et empêchent les conversations déplacées et les querelles $»{ }^{(12)}$

Aucune initiative n'est possible, tout est réglementé.

Le système progressif, mis en place par le règlement de 1930, consiste à placer le mineur dans une section d'observation où il fait l'objet « d'un examen physique et moral avec prise du niveau mental, l'observation attentive du caractère et la recherche de la nature de la perversité permettant d'effectuer un classement".

Ensuite le pupille est mis en section épreuve dont le règlement ne dit absolument rien si ce n'est que l'on sait par les témoignages qu'il s'agissait d'une structure cellulaire. C'est en fonction des gages d'amendement qu'il apporte, que le pupille passera en section " mérite » dont le régime est plus souple. Le renvoi en section " épreuve " pourra être prononcé au " vu de la moyenne mensuelle des notes journalières obtenues sur la conduite, le travail, et l'école ». ${ }^{(13)}$

Ce système dit progressif, fondé sur l'émulation, fut très vite critiqué, il reposait sur une sorte de confusion entre l'amélioration morale du jeune et l'adaptation à la vie institutionnelle. On le qualifia de pédagogie du caïdisme 
car le plus souvent, ce sont les petits caïds que l'on retrouvait en groupe " mérite ", les moniteurs les craignaient et ils savaient s'adapter aux normes de la vie institutionnelle. L'idée de rééducation en était encore à ses balbutiements et l'absence d'un personnel éducatif se faisait de plus en plus sentir.

\section{4-1937, les campagnes de presse contre les bagnes d'enfants.}

\section{L'apparition des moniteurs-éducateurs}

\section{Les campagnes de presse}

Le 18 avril 1934, dans une intervention à la Chambre, le député communiste Gabriel Péri évoque les 180 jeunes détenus de la maison d'éducation surveillée de Belle-Île dont 18 sont condamnés, les autres étant acquittés en tant que non-discernants. Péri demande qu'on retire à l'Administration pénitentiaire l'éducation des enfants. "L'enfance malheureuse a besoin de psychiatres, d'instituteurs et non de gardes chiourmes, il est indispensable que des éducateurs soient désignés en lieu et place des anciens policiers qui sévissent dans les bagnes d'enfants. » Dans ce même débat, un député, Guy Menant, plus marqué à droite, appuie les observations de Gabriel Péri.

Le garde des Sceaux, Georges Pernot, tout en couvrant les dirigeants des maisons d'éducation surveillée, exprime son accord " pour que les enfants placés dans les maisons d'éducation surveillée aient besoin d'éducateurs ».

La révolte des pupilles de la maison d'éducation surveillée de Belle-Île éclate trois mois plus tard. Elle marque, non pas le début, car la presse s'en est déjà saisie, mais le développement des campagnes de presse contre les bagnes d'enfants qui vont durer jusqu'en 1937, grâce au journaliste, Alexis Danan, et quelques autres dont l'écrivain Roger Vailland.

La révolte des pupilles de Belle-Île a été abondamment évoquée, elle donnera, quelques mois plus tard, la naissance d'un célèbre poème de Jacques Prévert «La chasse à l'enfant ». Prévert et Carné auront même un projet de film qu'ils ne pourront réaliser.

Sous l'impulsion d'Alexis Danan, les articles se multiplient dans la presse en faveur "des petits colons de Belle-Île " (Paris Soir, le 25 septembre 1934) qui de coupables deviennent victimes. Il évoque les « enfants martyrs en uniforme " et cite le cas d' " un jeune garçon de 4 ans et demi dans une maison de correction" (Paris Soir, le 3 octobre 1934). 
Le garde des Sceaux, Georges Pernot, dit sa ferme volonté d'assumer la protection de l'enfance. Les campagnes de presse sont connues des pupilles et favoriseront d'autres révoltes dont celle d'Aniane, en 1937.

L'Administration pénitentiaire est de nouveau au banc des accusés, l'opinion publique prend progressivement fait et cause pour les pupilles des maisons d'éducation surveillée. Il est à remarquer, pour expliquer cette évolution de l'opinion, qu'au milieu des années 1930, le chiffre de la délinquance des mineurs est très bas, peu d'enfants sont nés entre 1914 et 1918, la délinquance juvénile n'est pas perçue comme un danger social. C'est désormais le « milieu » qui constitue la figure de la dangerosité comme le reflète bien le cinéma.

Les pouvoirs publics se saisissent à nouveau de la nécessité qu'il y a à réformer les institutions pour mineurs de justice.

Toute une série de décrets, préparés par une commission parlementaire présidée par le député républicain modéré Louis Rollin, sur le thème de la protection de l'enfance, sont promulgués entre 26 octobre 1935 et le 30 octobre 1935. L'un d'eux dépénalise le vagabondage des mineurs en le faisant relever, au moins dans un premier temps, non plus de la peine mais de l'assistance éducative.

\section{L'apparition des moniteurs-éducateurs}

Un autre décret du 26 octobre 1935 crée au sein de l'Administration pénitentiaire l'emploi de moniteur-éducateur, le tiers des emplois vacants dans les maisons d'éducation surveillée est réservé aux candidats possédant le tout nouveau diplôme d'assistant social ou le certificat d'aptitude à l'enseignement des enfants arriérés, diplôme créé en 1909 pour les instituteurs chargés des enfants présentant des difficultés scolaires liées à leur manque de moyens. Loffre n'était pas très engageante, 900 francs par an, il n'y eut aucun candidat. En 1935, Henri Donnedieu de Vabres, professeur à la faculté de droit de Paris, crée avec Henri Van Etten, un quaker qui a longuement milité pour la fermeture du bagne de Cayenne, une ligue d'étude et de réforme du statut de l'enfance délinquante. La ligue publie un bulletin Pour l'enfance "coupable" qui sera l'organe de la réforme. Dix ans plus tard, ce bulletin, qui a changé plusieurs fois de nom, deviendra la Revue de l'Éducation surveillée. 
Un nouveau directeur est nommé à la tête de l'Administration pénitentiaire, Mainfroid Andrieu. Dans un rapport de juillet 1936, qu'il demande au psychologue J.-M. Lahy, membre de l'Ecole pratique des hautes études en psychologie appliquée, la conclusion mentionne : «La peine ne doit plus apparaître comme une sanction attachée à la faute mais comme une mesure susceptible d'améliorer le jeune dévoyé, de permettre sa rééducation. On ne doit plus le considérer comme un être déchu sur lequel la société se venge mais comme un malheureux qui a besoin d'être protégé, redressé. » (14)

Les formules ne sont pas nouvelles, on les trouvait déjà dans les travaux de la fin du XIXème siècle. Ce même rapport souligne la nécessite de remplacer les moniteurs par des instituteurs ou des travailleurs sociaux..., le directeur doit être un pédagogue connaissant la psychologie.

Concernant les pratiques avec les jeunes (on ne parle plus de pupille), il est recommandé le sport, les activités libres et des essais de self government. Le rapport conclut à la nécessité de la formation des personnels avec un lien entre la pratique et la recherche, un essai de coordination avec les autres secteurs de l'enfance et sur la pratique des autres pays.

Un projet qui correspond pleinement aux orientations autour de l'enfance et de l'éducation qui vont se développer dans le cadre du Front populaire.

\section{Vers la professionnalisation des éducateurs}

\section{6-1939 : Le temps des réformes, la génération des pionniers}

\section{Le début des réformes}

Une loi du 13 août 1936, proposée par le garde des Sceaux du gouvernement du Front populaire, Marc Rucart, crée un cadre d'éducateurs pour les maisons d'éducation surveillée dont la fonction est à la fois de "rééducation morale, formation professionnelle et maintien de la discipline ".

Cette même loi décide la réforme de la maison d'éducation surveillée de Saint-Maurice, à Lamotte-Beuvron, ancienne colonie pénitentiaire ouverte en 1872. Le personnel, précise la loi, n'est plus recruté directement par l'Administration pénitentiaire, il doit être détaché de l'Éducation nationale et de la direction de l'Enseignement technique. Un inspecteur général de cette direction, J. Roumajon, est chargé en mars 1936 d'inspecter la maison d'éducation
(14) J.-M. Lahy,

Rapport sur l'organisation de la nouvelle direction de l'éducation des jeunes délinquants, 13 juillet 1936, document consulté à la bibliothèque $2 \mathrm{RJ}$, CNFE-PJJ, Vaucresson. 
surveillée de Saint-Maurice. Un nouveau directeur est nommé, il vient de l'enseignement technique.

Enfin, l'Administration pénitentiaire et son nouveau directeur, Mainfroid Andrieu, prennent conscience qu'elle ne peut valablement se réformer sans faire appel à d'autres secteurs, ceux de l'éducation et de la formation professionnelle.

Si la direction de l'Enseignement technique, qui dépend à l'époque du ministère $\mathrm{du}$ Travail, répond favorablement à cette attente, l'Éducation nationale sera plus réservée quant à cette collaboration. Elle ne proposera comme candidats moniteurs-éducateurs qu'une quinzaine d'instituteurs surnuméraires ayant peu d'expérience pédagogique, ils sont toutefois volontaires, certains ont milité dans des mouvements de jeunesse.

Ils se retrouveront, en décembre 1936, dans le cadre d'un stage de formation de cinq semaines, organisé à la prison de Fresnes. La direction de ce stage est confiée à Jacques Guérin-Desjardins, commissaire général des Éclaireurs, qui a animé dans les années 1920 des soirées éducatives au patronage fondé à Paris par le juge Rollet, le premier juge des enfants de la loi de 1912. Marc Rucart et Jacques Guérin-Desjardins se connaissent et le scoutisme est, dans les années 1930, un mouvement en pleine effervescence ayant une pratique novatrice avec les adolescents.

Le programme du stage inclut des notions de droit enseignées par le président du tribunal pour enfants et adolescents de la Seine. Le docteur Georges Heuyer, qui a mené plusieurs travaux sur la délinquance juvénile, introduit la neuropsychiatrie infantile ; sur le plan pédagogique, interviennent Berthier, directeur de l'école des Roches à Verneuil-sur-Avre, qui parle des pratiques liées au scoutisme et à l'éducation anglo-saxonne : le self government, ainsi qu'un des futurs fondateurs des CEMEA. L'inspecteur Roumajon évoque la formation professionnelle.

À l'issue de ce stage, les quinze participants passent une semaine au centre d'observation de Möll en Belgique, où depuis 1912, l'instituteur Rouvroy a ouvert cet établissement, véritable prototype des structures d'observation pour mineurs délinquants.

La presse de l'époque est dithyrambique : «On prend soin d'équiper ces héros en vue de la tâche difficile qu'ils vont assumer " (Paris Soir, 10 janvier 1937). Tâche difficile c'est le moins qu'on puisse dire ! 
Dans son inspection de Saint-Maurice, Roumajon concluait au fait « que les seuls objectifs de l'institution qui regroupe 200 pupilles sont d'éviter les évasions et les faits d'ordre sexuel, d'occuper les pupilles à tout moment dans une simple optique de surveillance. Il s'agit d'un stage pénalisateur, pendant de longues années, exigé par une fatalité inéluctable sans autre utilité que sa durée ». ${ }^{(15)}$ Il propose que l'institution renonce à l'exploitation d'un domaine trop vaste, qu'elle se consacre à l'apprentissage de métiers correctement choisis, une instruction générale plus développée pour laquelle il pourrait être fait appel à l'enseignement technique. Enfin, il paraît nécessaire « de recevoir des adolescents dont la volonté manifeste de redressement, la bonne conduite et l'application au travail mériteront une aide particulière ». L'inspecteur Roumajon propose un modèle qui se réfere à celui de l'école professionnelle.

Début 1937, les moniteurs-éducateurs arrivent à Saint-Maurice, ils remplacent les anciens instituteurs de la Pénitentiaire dont trois restent affectés à l'éducation scolaire, les moniteurs continuent à remplir leur rôle de surveillance.

La nouvelle direction, confiée à un professeur de l'enseignement technique, a bien du mal à trouver sa légitimité auprès des personnels pénitentiaires, peu ou prou préparés à la réforme. L'effectif des pupilles, réduit à 200, en 1936, est réparti en groupes de 24 . Lorsque les moniteurs-éducateurs arrivèrent à SaintMaurice, ils eurent vite l'impression - certains l'écriront à Jacques GuérinDesjardins ${ }^{(16)}$ - « qu'on ne les attendait guère, nous étions là en surnombre, le mot d'ordre était ne rien changer ».

Très rapidement, les jeunes moniteurs-éducateurs, confrontés à des difficultés auxquelles ils n'avaient pas été préparés, ont du mal à y faire face, plusieurs abandonnent leurs fonctions, ce qui occasionne de nombreuses évasions de pupilles.

Henri Gaillac analyse les causes de cet échec dans son ouvrage Les maisons de correction : "Les campagnes de presse ont provoqué dans tous les établissements de violentes réactions des pupilles, l'application des méthodes libérales inspirées du scoutisme furent faites dans les plus mauvaises conditions, le nouveau directeur est très vite entré en conflit avec tous les personnels. " ${ }^{(17)}$ Cette première expérience échoue à peine entamée.

Une loi du 12 juillet 1937 prévoit la réforme de la maison d'éducation surveillée de Saint-Hilaire. Quelques moniteurs-éducateurs, formés à Fresnes, y
(15) J. Roumajon,

Rapport d'inspection sur la maison d'éducation surveillée de Saint-Maurice, mars 1936, document consulté à la bibliothèque 2RJ, CNFE-PJJ,

Vaucresson.

(16) Entretien de Michel Chauvière avec Jacques Guérin-Desjardin, mars 1980 .

(17) Henri Gaillac, Les maisons de correction, I8301945, Paris, Cujas, rééd 1991, p. 308. 
(18) Entretien de Jacques Bourquin avec Victor Ventré, mars 1981.

(19) Rapport Doublet, Fonds Brisset, versement $\mathrm{n}^{\circ}$ 20000111, Centre des archives contemporaines, Fontainebleau. seront nommés, mais il y a un refus manifeste du directeur de cette institution à cautionner cette expérience. Les moniteurs-éducateurs se trouveront très vite opposés à la direction et au personnel de surveillance, l'un d'eux, Victor Ventré, qui sera, après la guerre, directeur de Saint-Hilaire, dira : "Rien ne ressemblait à ce qu'on nous avait promis, le directeur ne croyait pas à la réforme et ménageait les personnels pénitentiaires. " ${ }^{(18)}$

On peut penser qu'en juillet 1937, cela en est fini des projets de réforme qui ne furent qu'une éclaircie dans une culture pénitentiaire ancrée dans ses pratiques et ses coutumes.

Toutefois, sur le plan législatif, les choses évoluent. Un décret du 17 août 1938 envisage la création d'un cadre distinct entre les personnels du service de l'Éducation surveillée et de la Pénitentiaire. Le passage du cadre d'une administration à l'autre sera subordonné à un tableau ministériel d'aptitude avec une garantie supplémentaire, la mutation dans le cadre d'une maison d'éducation surveillée ne sera possible que pour les seuls fonctionnaires titulaires du baccalauréat ou du brevet supérieur. Ce texte est essentiel car il met fin à l'interpénétration entre les deux administrations. Le même mois, à la demande du ministère de la Justice, J. Doublet, auditeur au Conseil d'État, rédige un projet de statut des éducateurs de l'Éducation surveillée.

Ce projet, qui ne verra pas le jour, préfigure les projets ultérieurs, en particulier celui d'avril 1945. Les conditions de recrutement des éducateurs sont celles des instituteurs non-normaliens. Autre élément important, les emplois de directeurs et de sous-directeurs des maisons d'éducation surveillée seront uniquement réservés aux éducateurs.

Ainsi s'affirme la primauté de l'éducatif sur les fonctions administratives ou les autres fonctions pédagogiques. Sont exclus de cette voie les enseignants professionnels sur lesquels, à la veille de la guerre, reposent les projets de réforme. On ne sait guère encore ce que sera la tâche des éducateurs, souvent perçue entre celle des instituteurs et des moniteurs. À la demande de l'Administration pénitentiaire, le projet Doublet évoque "leur statut disciplinaire et la définition de leur rôle ". ${ }^{(19)}$ Ils sont chargés de l'éducation physique, les marches incombant aux personnels moniteurs (surveillants) et aux éducateurs stagiaires ; ils veillent avec le surveillant général à la discipline de tous les instants, ils sont chargés de l'enseignement scolaire et des « veillées 
causeries ». On prévoit pour les éducateurs un régime spécial de vacances « pour éviter le désœuvrement des pupilles pendant les vacances scolaires ». ${ }^{(20)}$

\section{Hourcq, Courtois, Dhallenne : les réformateurs de Saint-Maurice et Saint-Hilaire}

Après les échecs de 1937, l’inspecteur général Bancal, dans un rapport de 1938, affirme " qu'il y a nécessité pour l'Administration pénitentiaire de ménager une période transitoire avant d'ouvrir ses portes à des cadres pédagogiques venus d'ailleurs et que dans un premier temps les fonctions de directeur soient réservées à des personnels issus de ses propres cadres à la suite d'une soigneuse sélection ». ${ }^{(21)}$

Début 1938, le directeur de l'Administration pénitentiaire désigne comme directeur de Saint-Maurice, Vincent Hourcq et comme sous-directeur, René Courtois. Le choix est judicieux, Vincent Hourcq, cadre administratif de la Pénitentiaire, acquis à l'idée de réforme depuis plusieurs années, est un adepte de la pédagogie des sports ; René Courtois avait été, en 1929, instituteur à la maison d'éducation surveillée de Saint-Hilaire, au début des années 1930, il avait été muté à la centrale de Poissy, en tant que commis-greffier, pour avoir, à la sortie de sa classe, joué au ballon avec les pupilles. C'était à la fois un avancement pour accéder à la hiérarchie, un instituteur devait passer par les services administratifs, mais c'était aussi une sanction.

En 1938, on se souvient de René Courtois comme un réformateur possible, les temps étaient en train de changer.

Le 22 septembre 1938, le garde des Sceaux, Paul Reynaud, sensible à la réforme et témoin de la dégradation à Saint-Hilaire où il fait une visite, destitue le directeur et le sous-directeur et fait nommer François Dhallenne, économe à l'administration centrale, un esprit novateur qui a des liens avec le scoutisme.

À Saint-Maurice, dont le quartier cellulaire a été détruit courant 1937 pour être remplacé par deux gigantesques ateliers Fer et Bois, les deux nouveaux responsables, qui collaborent avec l'inspecteur général Roumajon, s'efforcent d'en appliquer le projet. "La maison d'éducation surveillée, affirment-ils, ne doit être ni une prison, ni un hôpital mais une école professionnelle. " Ils sont à ce sujet plus proches des théories de l'éducation d'Henri Wallon qui a par-
(20) Ibid.

\section{(21) Jean Bancal,}

Rapport sur le fonctionnement des personnels éducatifs et pénitentiaires, Imprimerie administrative de Melun, 1938, p. 119. 
(22) Vincent Hourcq, Rapport de 1939, cité par Philippe Rey-Herme, in Quelques aspects du progrès pédagogique dans la rééducation de la jeunesse délinquante, Paris, Vrin, p. 136.

(23) Entretien de Jacques Bourquin avec René Courtois, juin 1986.

(24) Vincent Hourcq, Rapport de 1939, cité par Philippe Rey-Herme, op. cit., p. 137.

(25) Ibid., p. 147.

(26) Entretien de Jacques Bourquin avec René Courtois, op. cit. ticipé aux campagnes de presse contre les bagnes d'enfants, que des théories de la neuropsychiatrie infantile largement développées dans le secteur de l'enfance délinquante dans les années 1930 et qui aboutissent à une certaine médicalisation de l'inadaptation sociale.

Vincent Hourcq, dans un rapport de 1939, écrit, un an après sa prise de direction de Saint-Maurice : "On ne peut dire que les principes de l'éducation des pervertis, des délinquants, soient différents de ceux des enfants normaux, ils sont souvent les mêmes et ne varient que dans leur application. Ils exigent de l'éducateur une autorité plus affirmée ainsi que l'observation de certaines règles et mesures de précaution. " ${ }^{(22)}$

Le propos est intéressant en ce sens qu'il réintroduit le jeune délinquant dans le champ d'une certaine normalité pédagogique. Il est vrai que Vincent Hourcq et René Courtois n’avaient conservé comme "pupilles ", mais on commençait à dire "élèves ", que ceux qui manifestaient le désir d'un apprentissage de deux à trois ans. Pour les autres, ceux qui étaient là depuis plusieurs années, la réforme arrivait trop tard et ils furent envoyés dans d'autres maisons d'éducation surveillée.

En 1939, soit à peine un an après la réforme, « la majorité des élèves réussit le certificat d'études auquel, par le passé, on ne les présentait guère. Sur 15 mineurs présentés au CAP, 15 le réussissaient en moins d'un an de préparation ", nous dira René Courtois en 1986. ${ }^{(23)}$

Ce qui était essentiel dans cette réforme c'était le regard porté sur le jeune. On ne les considère plus comme des "inamendables " mais comme des jeunes dont il faut privilégier les potentialités de réussite.

" Il ne s'agit pas de mettre des jeunes dans l'impossibilité de nuire, mais surtout de former des hommes, les aider à gagner leur pain, tout en leur donnant un développement physique, intellectuel et moral qui leur permette de s'intégrer socialement. " (24)

Cette formation a comme support le groupe de 20-25 jeunes que Vincent Hourcq qualifie de "lieu de probité, de camaraderie, base nécessaire d'une vie en société, la morale est en action ou rien, l'homme ne se forme que par ses actes ». ${ }^{(25)}$ "Apprentissage de la volonté, de bonnes habitudes sociales non plus fondées sur la crainte du châtiment mais sur le souhait d'accéder à une meilleure vie ", précise René Courtois. ${ }^{(26)}$ 
Sont posées là les bases de ce qui deviendra, pendant la guerre et l'aprèsguerre, la rééducation où la formation professionnelle est l'élément majeur. René Courtois parle "d'apprentissage d'hommes, d'école d'énergie, de courage, d'une valorisation du travail, de la classe ouvrière à laquelle ces jeunes appartiennent $»{ }^{(27)}$

À Saint-Maurice, en 1938-1939, l'instructeur est le personnage essentiel, il le restera longtemps, l'éducateur, en contact avec le groupe de jeunes qu'il encadre, doit trouver son identité au travers de son vécu avec eux.

Cette vision très positive du projet de Saint-Maurice doit toutefois être nuancée. Si le quartier cellulaire a été détruit, il subsiste des mitards et les jeunes coucheront encore longtemps dans les " cages à poules " dans le groupe «épreuve » qui deviendra le groupe d'accueil.

Vincent Hourcq et François Dhallenne continuent à fonder leur projet sur le système progressif élaboré en 1930, mais le passage à la section supérieure, " honneur ", " excellence ", est davantage fondé sur une connaissance du jeune que sur son conformisme.

Si le problème de la sanction de la section disciplinaire demeure, François Dhallenne analyse le système des punitions et s'oppose formellement aux châtiments corporels. Il dénonce " cette fiction qui serait l'égalité en matière de punition : une simple réprimande adressée à un jeune émotif provoque bien souvent un choc bien plus violent et plus salutaire qu'une punition d'isolement infligée à un pervers ". ${ }^{(28)}$

Il y a un souci d'individualisation lié à une connaissance réelle du jeune qui s'inscrit totalement en rupture avec les pratiques antérieures des maisons d'éducation surveillée.

C'est à cette école que seront formés les premiers moniteurs-éducateurs de Saint-Maurice, et de Saint-Hilaire, l'une Saint-Maurice privilégiant la formation professionnelle et les sports, la seconde, Saint-Hilaire plus centrée sur une formation de type artisanal, sur la vie du groupe et les loisirs. Victor Ventré évoque l'apparition des loisirs avec les jeunes, en 1938-1939, à Saint-Hilaire : "Nous sortions des principes pénitentiaires fondés sur la crainte et la dénonciation, on essayait d'abandonner l'aspect occupationnel pour le remplacer par quelque chose de plus positif pour les jeunes. Avec Dhallenne, on introduisait des soirées veillées, des jeux, lui-même participait à certaines scénettes. » ${ }^{(29)}$
(27) Ibid.

(28) Vincent Hourcq, Rapport de 1939, cité par Philippe Rey-Herme, op. cit., p. 150.

(29) Entretien de Jacques Bourquin avec Victor Ventré, $o p$. cit. 
(30) François Rimaire,

Jeunes reclus, souvenirs de galère et d'éducation active, Ramonville-Saint-Agne, Erès, 1999, p. 31 sqq.

(31) Ibid.

(32) Entretien de Michel Chauvière avec Jacques GuérinDesjardins, op. cit.
On se situe, il est vrai, dans les années qui suivent immédiatement 1936. Le temps des loisirs conquiert une reconnaissance de droit pour toutes les couches sociales, les maisons d'éducation surveillée s’inscrivent dans ce courant dont la jeunesse est un des principaux bénéficiaires.

Pour les jeunes moniteurs-éducateurs, dont le rôle est encore imprégné des fonctions de surveillance, c'est un moyen de définir avec les jeunes d'autres champs d'activité, c'est aussi s'approprier par rapport aux instructeurs techniques un domaine qui leur soit propre. Mais le contexte reste difficile.

François Rimaire fut un des premiers moniteurs-éducateurs de SaintHilaire. Il a publié en 1999, sous un nom d'emprunt, ses souvenirs d'éducateur. Les premiers chapitres concernent la période 1938-1939. Il arrive à Saint-Hilaire en novembre 1938, sortant du service militaire, il a été très motivé par les campagnes de presse, ce sont les premières semaines de la réforme : "La réforme commence à peine, notre petit monde d'éducateurs, sans uniforme, doit s'occuper d'une centaine de pupilles, les plus jeunes, ils ont entre 14 et 16 ans, nous travaillons avec deux enseignants et 6 moniteurs d'atelier. Dans la cour, les surveillants, clés en main en permanence, arpentent les trottoirs pendant que nous jouons avec les pupilles, ils apprennent très vite les règles du ballon, du jeu de barres. Bien sûr, les grands se moquent, ils invectivent car ils voient là échapper à leur emprise ou à leurs sollicitations tabagiques ou autres, les plus jeunes. Les caïds sentent leurs privilèges menacés, les surveillants s'inquiètent pour leur emploi et nous attendent au tournant, guettant l'erreur qui nous amènera des ennuis de la part des garçons ou de l'administration. " ${ }^{(30)}$

Au mitard, qui subsiste avec ses vingt cellules - on ne l'a pas détruit comme à Saint-Maurice -, « les pupilles tondus, en chaussettes, pantalon sans ceinture, n’ont aucune occupation, seules les rations alimentaires ont été améliorées ». (31)

\section{Quelques éléments sur les moniteurs-éducateurs de cette époque}

Nous n'avons trouvé que des éléments très parcellaires les concernant. Parmi les vingt instituteurs recrutés dans le cadre de l'Éducation nationale en 1936, très peu sont restés. Jacques Guérin-Desjardins, l'animateur de la session de formation de Fresnes, dit dans un entretien de $1980,{ }^{(32)}$ que « la plupart d'entre eux n'étaient pas motivés à l'exception de quelques-uns, anciens parti- 
cipants de mouvements de jeunesse ». Rappelons qu'il ne s'agissait que d'instituteurs surnuméraires et sans emploi.

Parmi la dizaine d'autres pour lesquels nous avons retrouvé quelques éléments, on doit distinguer ceux qui venaient de la Pénitentiaire où ils étaient instituteurs, enseignants techniques ou moniteurs intégrés comme moniteurs-éducateurs en 1937, puis ceux recrutés en 1937 et 1938, dans le cadre des campagnes de presse contre les bagnes d'enfants en tant que moniteurséducateurs, rien ne les prédisposait dans un premier temps à s'occuper des problèmes de l'enfance coupable. L'un dit dans un entretien : " J'étais bachelier, comptable à l'Électricité, pendant mon service militaire j’avais entendu parler des campagnes de presse, j’avais posé ma candidature pour Saint-Hilaire, elle fut acceptée. J'avais fait les grèves de 1936, j'étais mal vu à l'Électricité, je savais que je ne pourrais rester. " ${ }^{(33)}$

Parmi ces derniers, deux sont licenciés en droit, un a le certificat d'aptitude pédagogique, un autre est bachelier, les deux autres ont le BEPS et le brevet. Pour les licenciés en droit, est-ce l'engouement pour l'œuvre à remplir qui les motive ? C'est vraisemblable pour Jean Buzenac, entré à Saint-Hilaire en 1937. Il sera directeur dès la fin de la guerre puis deviendra juge des enfants dans les années 1960 .

Les autres dont nous connaissons les noms : R. Pailhès, V. Ventré, J. Cambus, R. Meurillon, seront tous, après la guerre, directeurs des premières institutions de l'Éducation surveillée devenue indépendante de l'Administration pénitentiaire.

Ces éducateurs ont une identité encore bien incertaine. Jean Dublineau, médecin psychiatre à l'hôpital de Ville-Evrard et qui appartient au courant de la neuro-psychiatrie infantile, s'intéresse à ce nouvel éducateur dans un numéro de 1939 de Pour l'enfance "coupable". L'auteur, qui se réfere à la fois au surveillant, au maître d'internat, lui donne comme fonction «d'assurer la prise en charge d'enfants en état d'orphelinat moral ». ${ }^{(34)}$ Par cet euphémisme, il désigne les enfants qui relèvent de la Justice. "C'est, poursuit le Dr Dublineau, "un rôle éminemment social"... l'éducateur est le personnel de base de l'internat où il aura à être en contact avec l'instituteur, le maître d'atelier, le psychologue, à lui seul il sera un peu tout cela suivant les heures et les circonstances. Il sera l'émanation du cadre de la nouvelle famille où se remodèleront les tendances des

(33) Entretien de Jacques Bourquin avec Victor Ventré, op. cit.

(34) Jean Dublineau, Pour l'enfance "coupable", $\mathrm{n}^{\circ} 29$, mai-juin 1939. 
pupilles, où devront s'élaborer leurs nouveaux réflexes sociaux. " "(35) Image d'un internat de rééducation à venir, à construire, où l'éducateur, personnage polymorphe, au carrefour de plein de fonctions nouvelles, doit trouver son identité.

La voie est ouverte pour les expériences à venir.

\section{2-1945 : la génération des moniteurs-éducateurs de la guerre}

C'est aux alentours de 1942-1943, qu'apparaît la profession d'éducateur dans le secteur privé de l'enfance "irrégulière ». De manière beaucoup plus réduite, le service de l'Éducation surveillée de l'Administration pénitentiaire reprend ses activités de réforme fin 1942 et fait appel à des moniteurs-éducateurs, dans la continuité de ce qui avait été réalisé en 1938-1939.

Le traumatisme de la défaite en juin 1940, l'exode, plus d'un million de prisonniers, l'occupation de la moitié du territoire national par l'armée allemande, amènent beaucoup d'adolescents à être plus ou moins laissés à euxmêmes. Fin 1940, les prisons, les établissements pénitentiaires pour mineurs sont remplis de jeunes. À la maison d'éducation surveillée de Saint-Hilaire, ils sont plus de 400, une révolte éclate le 18 juin 1940, le jour où les Allemands franchissent la Loire, à Saumur (Paris Soir, 14 décembre 1940).

Le gouvernement de Vichy, dès son installation, début juillet 1940, très préoccupé du sort de la jeunesse, envisage un véritable encadrement de celleci avec peut-être en ligne de mire, un objectif d'endoctrinement. Dans le contexte de la défaite, dont le nouveau pouvoir en place rend les adultes responsables et en particulier les instituteurs, il faut, écrit-on, construire de nouvelles valeurs pour la jeunesse.

Dès juillet 1940, en France non-occupée, les chantiers de jeunesse vont remplacer le service militaire. Le projet s'inspire à la fois de l'armée et du scoutisme, les jeunes qui ont l'âge du service militaire devront participer pendant un an à de grands chantiers de forestage, les valeurs qui y sont développées reposent sur le respect du chef, la vie en groupe, le travail, la solidarité, les loisirs, le retour vers le monde rural. Pour les plus jeunes, ceux qui ont entre 16 et 18 ans, le secrétariat général à la Jeunesse crée un mouvement inspiré des chantiers de jeunesse, ce sera les Compagnons de France, destinés à intervenir auprès de ceux qui risquent de devenir chômeurs. L'heure est à l'encadrement et à l'éducation. 
En ce qui concerne l'Administration pénitentiaire et le service de l'Éducation surveillée, un décret du 25 février 1940, avait modifié l'appellation des maisons d'éducation surveillée, elles devenaient des institutions publiques d'éducation surveillée (IPES).

Ce changement de nom signifiait-il la poursuite des réformes de 1937-1938? Souvenons-nous que les maisons d'éducation surveillée avaient succédé aux colonies pénitentiaires! Ce ne fut pas le cas, un décret du 31 août 1940 rétablissait l'interpénétration du cadre pénitentiaire et de celui de l'éducation surveillée, c'était un retour en arrière. Cette décision était-elle liée aux incidents de juin 1940 à Saint-Hilaire et au surpeuplement des nouvelles IPES ? On peut le supposer, les consignes disciplinaires et sécuritaires redevenaient prioritaires. Il n'y aura plus de recrutement de moniteurs-éducateurs jusqu'en 1942.

En 1941, l'inspecteur Jean Bancal, dans son Essai sur le redressement de l'enfance coupable, s'opposait à ce qu'il appelait un retour en arrière et demandait "que l'on spécialise les personnels éducatifs, que le directeur se consacre surtout aux tâches éducatives et que leur soit adjoint un économe pour les travaux liés à la gestion ». Et d'ajouter : "Il est nécessaire que les IPES ne soient plus englobées dans les circonscriptions pénitentiaires et que les directeurs relèvent directement du ministre et accessoirement du préfet du département. " ${ }^{(36)}$ Il allait plus loin que les réformateurs de 1937-1938.

Ce rapport, qui n'aura aucun effet, concluait à une mise à distance de plus en plus grande de l'Éducation surveillée avec l'Administration pénitentiaire. Jean Bancal allait jusqu’à écrire : "Il faut prononcer à l'égard de l'Administration pénitentiaire une sorte de déchéance de la puissance paternelle. " ${ }^{(37)}$

\section{Les premiers éducateurs du secteur privé}

- La circulaire du 21 mars 1942 sur la détention provisoire des mineurs

Le garde des Sceaux, Joseph Barthélémy, invite les procureurs généraux à supprimer toute détention provisoire pour les mineurs : " À une époque où l'ensemble des problèmes soulevés par la législation de l'enfance traduite en justice fait de la part de mes services l'objet d'une étude minutieuse dominée par le souci de la réadaptation sociale du jeune délinquant, j'estime qu'une des conditions préalables de cette réadaptation consiste dans la suppression de l'incarcération des mineurs prévenus. " ${ }^{(38)}$
(36) Jean Bancal, Essai sur le redressement de l'enfance coupable, Paris, Recueil Sirey, 1941, p. 71.

(37) Ibid, p. 64.

(38) Cité in Hommage à Pierre Ceccaldi, Imprimerie administrative de Melun, 1970, p. 108. 
(39) Ibid, p. 107.
La circulaire est rédigée par Pierre Ceccaldi, chef du service de l'Éducation surveillée. Le garde des Sceaux invite les substituts « à rechercher au siège du tribunal ou dans les environs immédiats, un établissement public ou privé ou encore une personne charitable, susceptible de prendre en charge un enfant en attendant que l'autorité judiciaire ait statué sur son cas ». ${ }^{(39)}$

Cette circulaire qui s'inscrit dans la continuité des débats de l'avant-guerre ne cache-t-elle pas un autre problème? Depuis 1940, les prisons sont pleines de mineurs alors que l'on va avoir besoin de places pour d'autres détenus à venir : les résistants.

La conséquence de la circulaire sera la création, dès mi-1942, dans le secteur privé de l'enfance " irrégulière », de petits centres d'accueil pour recevoir des mineurs délinquants avant jugement. Ces centres sont ouverts le plus souvent en pleine campagne, comme les colonies agricoles de 1840, dans une croyance aux vertus rédemptrices du monde rural dont le régime de Vichy est porteur.

Dès août 1941, devançant la circulaire de mars 1942, une assistante sociale, Anne-Marie de La Morlais, avait ouvert avec quelques anciens scouts, un centre d'accueil dans une ferme à Kergoat, en Bretagne, pour recevoir des jeunes confiés par les tribunaux qui voulaient leur éviter la prison. Anne-Marie de La Morlais avait même prévu une formation pour les jeunes cadres scouts qui l'accompagnaient et qu'elle appelait des chefs rééducateurs. Ces petits centres d'accueil se multiplient en 1943, on en compte 35 dans le secteur privé.

- La loi du 27 juillet 1942 sur l'enfance délinquante

Cette loi qui généralise les tribunaux pour enfants et accorde une importance majeure au centre d'observation supprime la notion de discernement pour la remplacer par celle d'éducabilité du mineur délinquant. La loi ne sera en fait pas appliquée mais l'ordonnance du 2 février 1945, sur l'enfance délinquante, s'en inspirera.

C'est à partir de novembre 1942 que dans le cadre des associations régionales de Sauvegarde de l'enfance et de l'adolescence, missionnées par l'État, se créent les premières écoles privées d'éducateurs à Montpellier, Lyon, et à Montesson près de Paris. Il existait déjà une école ouverte, à Toulouse, en 1941.

La profession d'éducateur est en train de naître dans le secteur privé. Impulsé par un psychiatre, Georges Heuyer, et par un magistrat, Jean Chazal, conseiller 
du ministre de la Santé en 1943, se constitue un conseil technique de l'enfance déficiente et en danger moral, dont le rôle sera, en référence aux centres d'observation et aux centres d'accueil et de triage, d'aborder le problème de la nomenclature des inadaptations, des problèmes de dépistage, d'observation et de reclassement dans la vie sociale. Ce conseil est surtout composé de médecins, Georges Heuyer, Jean Dublineau, Louis Le Guillant et Daniel Lagache. Nous retrouverons ce dernier dans les centres d'accueil de l'Éducation surveillée.

\section{Les moniteurs-éducateurs de l'Éducation surveillée}

- Que se passe-t-il à cette période à l'Éducation surveillée?

Rappelons que toute velléité de réforme est stoppée depuis le décret d'août 1940, l'IPES de Saint-Hilaire a fait l'objet d'une grave révolte en juin 1940, l'IPES de Saint-Maurice est occupée par les Allemands et transférée fin 1940 à Aniane, un établissement de l'éducation surveillée, non réformé. Les deux réformateurs de Saint-Hilaire et Saint-Maurice, René Courtois et François Dhallenne, seront prisonniers en Allemagne jusqu'à la fin 1941. L'IPES de Belle-Île sera fermée en 1942, au moment du mur de l'Atlantique et les pupilles repliés sur Saint-Maurice. En ce qui concerne les établissements de filles, anciennes écoles de préservation, Clermont de l'Oise est transférée à la maison d'arrêt de Rennes, Doullens est détruite par un bombardement, seule subsiste Cadillac, sur les bords de la Garonne.

La circulaire du 21 mars 1942, dont on sait qu'elle fut préparée par le service de l'Éducation surveillée, sera à l'origine de l'ouverture de 4 centres d'accueil et de triage à Paris et dans le département de la Seine, le plus souvent dans des enceintes pénitentiaires ou militaires. En fait, sous couvert de supprimer la détention provisoire, on ne faisait que transférer cette détention dans d'autres locaux. François Dhallenne, les évoquant à la fin de la guerre, dans un rapport à l'inspecteur Pinatel, écrit : «Ce sont des établissements créés dans une improvisation hâtive qui ignore toutes les réformes d'avant-guerre. »(40)

- Les circonstances de la venue des moniteurs-éducateurs

Malgré une référence pénitentiaire évidente, en particulier aux Tourelles et à la rue de Crimée, le service de l'Éducation surveillée souhaite introduire dans ses centres d'accueil une dimension éducative dans la logique de la cir-
(40) Cité par Christian Sanchez, « Les centres d'accueil et de triage de l'Éducation surveillée, 1941-1950", le Temps de l'histoire, $\mathrm{n}^{\circ} 1$, février 1998, p. 128. 
(41) Entretien de

Jacques Bourquin avec Jacques Seidel, juillet 1980. culaire du 21 mars 1942, et la primauté accordée à l'observation des mineurs délinquants par la loi du 27 juillet 1942.

Dans le cadre des IPES, les retours en 1941 de René Courtois et François Dhallenne, après 18 mois de captivité en Allemagne, vont favoriser à SaintMaurice et à Saint-Hilaire la reprise des réformes de 1938-1939.

Un autre élément très important, dont l'Éducation surveillée se servira pour recruter de nouveaux personnels, est l'apparition du Service du travail obligatoire (STO) en Allemagne, dès 1942. Suite à des accords passés entre le gouvernement de Vichy et l'État allemand, les jeunes français qui relèvent des classes 1942-1943 peuvent être requis pour aller travailler dans les usines allemandes où il s'agit de remplacer les ouvriers allemands enrôlés dans l'armée du Reich. Ce sera un accord de dupes, il était prévu qu'en échange, les prisonniers français en Allemagne pourraient être libérés. Ce point de l'accord fut à peine tenu. Beaucoup de jeunes français rejoindront la résistance naissante pour échapper au STO. Il était prévu, dans les accords, que les jeunes qui s'engageraient dans les services dépendant des ministères de l'Intérieur et de la Justice, pourraient échapper au STO. Ce fut une opportunité pour le service de l'Éducation surveillée qui en profita pour recruter des moniteurs-éducateurs. C'était un moyen pour faire entrer dans les quelques établissements, IPES et centres d'accueil, des jeunes gens totalement extérieurs à la référence pénitentiaire dont on espérait qu'ils seraient, dans leur rapport avec les pupilles, porteurs de références nouvelles. On retrouvait ce souci des années 1938-1939 : réformer avec des gens venant de l'extérieur.

Les premiers moniteurs-éducateurs venaient souvent de passer un an dans les chantiers de jeunesse, aux Compagnons de France, où ils avaient vécu à l'heure de la vie en groupe, du retour à la nature ; "l'éducation se faisant au travers des actes de la vie, à l'atelier, aux champs, en marchant, en chantant, à la veillée. " ${ }^{(41)}$ Tout cela, très empreint de scoutisme, valeurs qui pourraient convenir à un idéal de rééducation à proposer à de jeunes délinquants vécus le plus souvent comme victimes de la guerre.

Tout un réseau d'informations sur " la planque " Éducation surveillée se constitue.

Joseph Villier, recruté aux Tourelles en 1943 comme moniteur-éducateur, évoque « ce recrutement qui se faisait de bouche à oreille, personne n'officia- 
lisait la planque, je l'ai su par un copain dont le père travaillait à la Pénitentiaire. Pierre Ceccaldi, responsable de l'Éducation surveillée, était très acceptant, il favorisait des gens comme nous. J'étais instituteur ». ${ }^{(42)}$

Un autre moniteur-éducateur, Jacques Seidel, recruté à Saint-Jodard en janvier 1944, venant de passer un an comme encadrant aux Compagnons de France, explique : " J'avais vu la répression des grèves de 1936, j’étais très branché là dessus, j’étais issu du monde ouvrier. Aux Compagnons, j’avais été influencé par les discours du Maréchal, ce qu'il fallait faire pour être bien comme tout le monde, mais en même temps, je sentais dans le discours Travail-Famille-Patrie un discours aristocratique de classe qui me dérangeait. Il y avait les gens bien et les autres. Je ne savais pas très bien où j'étais. " ${ }^{(43)}$

On ressent chez les moniteurs-éducateurs ce sentiment de flou dans une occupation qui dure et dont on ne prévoit pas l'issue en 1943.

Leur première motivation est d'échapper au STO, d'être à l'abri, tout en s'occupant des jeunes. Beaucoup proviennent de l'enseignement, des mouvements de jeunesse, ils ont un savoir dans ce domaine.

Paul Lutz, qui est inspecteur à l'Éducation surveillée en 1943-1944, évoque les moniteurs-éducateurs qu'il rencontre à Saint-Hilaire : "Des jeunes instituteurs, des étudiants en médecine, des dominicains, c'était un personnel de haut niveau...»Et non sans une certaine nostalgie, il ajoute : "Ils ont presque tous quitté Saint-Hilaire à la Libération. " ${ }^{(44)}$ On n’était pas encore à l'heure de la professionnalisation.

À la même époque, Henri Joubrel, qui sera à l'origine de la création du métier d'éducateur dans le secteur de l'enfance inadaptée, visite SaintMaurice. Il dépeint « de jeunes bacheliers poursuivant des études supérieures, ils ont de l'allure, de l'aisance... ils sont à la hauteur du rôle extraordinairement important qui leur est confié ". ${ }^{(4)}$

Pour Saint-Hilaire, Saint-Maurice, ces nouveaux venus sont une aubaine, ils contribuent à inventer un espace éducatif dans les institutions pénitentiaires pour mineurs. Victor Ventré, recruté comme moniteur-éducateur à Saint-Hilaire en 1937, s'occupe de la troupe scoute qui vient d'être créée en 1943 : «C'était un moment très bénéfique, nous avions plein de gens qui arrivaient pour échapper au STO, il n'y avait pas d'empêcheurs de tourner en rond, on partageait nos joies avec les mineurs, on était proche les uns des autres... " (46)
(42) Entretien de

Jacques Bourquin avec Joseph Villier, juin 1980.

(43) Entretien de Jacques Bourquin avec Jacques Seidel, op. cit.

(44) Entretien de Jacques Bourquin avec Paul Lutz, mars 1987.

(45) Henri Joubrel,

« Promenade à travers les maisons d'enfants de la Pénitentiaire ", Pour l'enfance "coupable", n' 53, mars 1944 .

(46) Entretien de Jacques Bourquin avec Victor Ventré, op. cit. 
(47) Entretien de Jacques Bourquin avec André Bernard, janvier 1981.

(48) Entretien de Jacques Bourquin avec A. Perrot, février 1993.

(49) François Rimaire, Jeunes reclus..., op. cit.

(50) Entretien de Jacques Bourquin avec Joseph Villier, op. cit.
Dans le même registre, André Bernard, instituteur entré comme moniteuréducateur en 1943, montre l'opposition avec les personnels pénitentiaires : "On n’avait pas beaucoup réfléchi à la question des jeunes, mais si les surveillants (on disait "les gaffes" comme les gosses) les considéraient comme de la racaille, nous avions des relations privilégiées avec eux. L'institution était encore en plein dans le système répressif, les gosses qui étaient au groupe d'honneur, c'était un système faussé que nous critiquions. " ${ }^{(47)}$

A. Perrot, recruté comme moniteur-éducateur en juillet 1942, évoque la section de fermeté de Saint-Hilaire. "Ils avaient le crâne rasé, des sabots en bois, ils pouvaient y faire des séjours de 3 à 4 mois, c'est dire combien ceux qui n'arrivaient pas à s'adapter devaient s'incliner à force de discipline. " (48)

Que ce soit à Saint-Maurice, très centrée depuis 1938 sur la formation professionnelle ou à Saint-Hilaire, on était dans des institutions de type très contradictoire où les archaïsmes pénitentiaires les plus forts s'efforçaient de cohabiter avec quelques innovations inspirées du scoutisme et de l'éducation.

François Rimaire, déjà rencontré comme moniteur-éducateur en 1938, disait de François Dhallenne en 1943 : «Il ne voulait rien brusquer, conscient de la complexité de la situation, comme de sa responsabilité de mener une mission à la fois administrative et pédagogique. " ${ }^{(49)}$

Lassé de la lenteur de la réforme, François Rimaire allait quitter SaintHilaire en 1943 pour s'engager dans le secteur privé, celui des petits centres d'accueil, plus créatifs, plus dynamiques et qui ne traînaient pas avec eux cent ans de passé pénitentiaire.

Nombre de moniteurs-éducateurs furent nommés dans les centres d'accueil de la région parisienne. Joseph Villier, évoquant les Tourelles, dit : "C'est une véritable prison avec des barbelés et des miradors. " Il nous décrit son premier contact avec les gosses : "On me fait entrer dans un dortoir de 40 châlits, six types faisaient de la lutte, ils étaient impressionnants, ils me voient, se mettent au garde à vous, je suis resté là deux heures avec eux et nous avons fait connaissance. " ${ }^{(50)}$

Le travail du moniteur-éducateur aux Tourelles : 3 heures d'intervention le matin, 3 heures l'après-midi, chaque demi-journée est rythmée par une heure de classe, une heure avec le groupe en dortoir, une heure sur la cour ; le reste du service est effectué par les surveillants. 
Le quotidien y est très rude. Dominique Colombani, affecté comme moniteur-éducateur en 1943, évoque le problème de la nourriture : «En passant par les cuisines au rez-de-chaussée, il y avait des monticules de trognons de chou, le chou c'était la nourriture de base de la maison, les garçons en cachette ramassaient ces trognons, ils se cachaient dans les tinettes pour les manger crus le soir au dortoir, c'était bien sûr interdit... " ${ }^{(51)}$

Le même Dominique Colombani accompagne un jour un jeune au centre d'accueil de Villejuif, il est impressionné : "Il y avait deux grandes salles de dortoir avec 25 lits tout blanc, tout était propre, de grandes fenêtres, un réfectoire avec de vrais repas, une grande cour avec des arbres, on y organisait des jeux, des matchs de football... C'était l'Amérique ! " (52)

Il est vrai que Villejuif était ouvert dans un espace hospitalier, le responsable Jean Buzenac avait été recruté comme moniteur-éducateur à SaintHilaire en 1937. Ancien scout, il avait essayé de créer un espace éducatif. Villejuif, du fait de sa proximité avec l'hôpital psychiatrique, travaillait très en relation avec le psychiatre Daniel Lagache et une jeune psychotechnicienne, Raïssa Rikkers, qui fera ensuite une longue carrière à l'Éducation surveillée en tant que psychologue.

Le centre de la rue de Crimée, dans une référence plus pénitentiaire, avait aussi un souci d'observation. Le docteur Marguerite Badonnel, qui avait été à l'origine en 1934 du service médico-psychiatrique de la maison d'éducation surveillée de Fresnes, intervenait rue de Crimée avec un psychologue. Dans un rapport, Jean Pinatel, inspecteur général des services de l'administration, évoquait le lien entre service psychologique et service éducatif. "Il faut établir une interpénétration étroite entre ces services. Cette liaison permettra de faire profiter les psychologues des leçons de l'expérience et du bon sens et permettra aux éducateurs de ne pas céder à l'empirisme. " ${ }^{(53)}$

L'inspecteur avait une vision assez curieuse de la psychologie. Quelques années plus tard, il sera une des figures marquantes de l'école criminologique française.

Il y avait certainement à Villejuif et à Crimée une amorce d'observation, mais Robert Leréverend, qui était moniteur-éducateur à la rue de Madrid, se souvient que pour les jeunes, l'observation débouchait le plus souvent sur « la vingt et une [le placement jusqu'à 2I ans] à Saint-Hilaire, Saint-Maurice ou Aniane et
(51) Dominique

Colombani, Pour

l'Histoire, Bulletin de l'AHES-PJM, nº 38, avril 2005.

(52) Ibid.

(53) Jean Pinatel,

Rapport d'inspection de la rue de Crimée, 30 mars 1944, conservé au Centre des archives contemporaines de Fontainebleau et à la bibliothèque $2 \mathrm{RJ}$ de Vaucresson. 
(54) Robert Lerévérend,

Pour l'Histoire, Bulletin de l'AHES-PJM, n 40 , décembre 2005.

(55) Entretien de Jacques Bourquin avec Joseph Villier, op. cit. parfois le placement dans des patronages parisiens qui plaçaient les enfants comme apprentis ou garçons de ferme $"{ }^{(54)}$

L'observation nécessitait certainement une gamme d'institutions de sorties plus larges. Il faudra des années pour qu'elles apparaissent.

Pour compléter ce regard sur les institutions de la guerre, l'Éducation surveillée venait d'ouvrir en 1943 une nouvelle IPES à Saint-Jodard, un ancien préventorium, dans les Monts du Forez, à $40 \mathrm{~km}$ de la ville la plus proche Roanne. La référence du retour à la nature demeure avec l'ouverture, en 1943, d'un chantier de forestage à Marlotte dans la forêt de Fontainebleau, créé sur le modèle des chantiers de jeunesse et dirigé par un capitaine dégagé des cadres de l'armée. Joseph Villier, qui y fut moniteur-éducateur, évoque " le retour à la terre avec l'hébertisme, les relents de camp de jeunesse, l'apprentissage scolaire et les loisirs étaient privilégiés. Les gosses travaillaient à la coupe de bois sous la responsabilité de forestiers professionnels ". ${ }^{(55)}$

À la libération, Marlotte recevra en tant que "pupilles ", et dans un contexte beaucoup plus disciplinaire, les jeunes miliciens de moins de 18 ans qui seront ensuite envoyés à l'IPES de Belle-Île entre 1945 et 1946.

\section{- Les éléments concernant ces jeunes moniteurs-éducateurs}

Nous n'avons retrouvé que les dossiers des moniteurs-éducateurs, restés à l'Éducation surveillée après la guerre soit une cinquantaine. Près de la moitié a été recrutée dans les centres d'accueil de Paris et du département de la Seine. L'autre moitié : 7 à Saint-Hilaire, 5 à Marlotte, 4 à Saint-Maurice, 4 à Saint-Jodard, 4 à Aniane.

Le recrutement fut presque toujours régional, voire même local. En province, c'est le directeur d'IPES qui recrute, un moyen de permettre une meilleure connaissance du candidat qui vient de l'environnement et de bénéficier de renseignements précis sur sa filiation, prouver que l'on n'est pas juif et sur la non-appartenance à des sociétés secrètes.

Ils sont en règle générale issus d'un milieu social modeste (petits commerçants, artisans, ouvriers). Leur âge moyen se situe entre 21 et 25 ans. 12 sont de la classe 1942.

Leur bagage intellectuel est assez divers, n'oublions pas qu'à partir du décret d'août 1940, seuls les moniteurs sont recrutés comme titulaires, les 
moniteurs-éducateurs ne sont que contractuels :

- 6 d'entre eux avaient entamé des études supérieures (droit, lettres)

-6 sont titulaires du CAP d'instituteur

- 10 sont bacheliers

-8 ont le brevet élémentaire

- 10 ont le certificat d'études primaires.

La moitié d'entre eux n'a pas d'antécédents professionnels. Parmi les autres :

- 11 instituteurs, le plus souvent intérimaires

- 4 employés de banque, PTT

-4 ouvriers

-1 journaliste

- 1 gardien de la paix

- 1 séminariste.

L'immense majorité a cherché à échapper au STO ; une dizaine d'entre eux ont fait un an dans les chantiers de jeunesse ; le scoutisme est rarement évoqué, il est vrai que le dossier d'admission de 1943 n’y fait pas référence.

- L'univers des moniteurs-éducateurs à l'intérieur des institutions

À partir d'entretiens avec quelques-uns d'entre eux et de témoignages écrits, nous avons essayé de dégager ce qu'ils vivaient dans les institutions, les types de rapports qu'ils établissaient avec les jeunes, les autres personnels, où se situaient leurs espérances. Très rapidement revient un élément majeur : c'est la proximité qui existe entre les "gosses » et eux-mêmes, cette proximité pouvant être parfois vécue par l'institution comme une complicité.

- Proximité entre les moniteurs-éducateurs et les pupilles.

C'est tout d'abord une proximité fondée souvent sur l'âge ; les jeunes ont entre 16 et 21 ans et les moniteurs-éducateurs guère plus de 20 ans. Jacques Seidel dit : "J'avais 20 ans comme les plus grands, j'étais très impressionné par l'un d'eux qui avaient déjà un gosse. " ${ }^{(56)}$

Cette proximité est aussi fondée sur l'insécurité de l'époque. Pour les jeunes, la guerre, les séparations familiales accentuées par l'exode et les pères souvent prisonniers les ont plus ou moins laissés à eux-mêmes, à la merci de n’importe quelle expérience dont les conséquences sont difficilement mesurables, ils ont été les petites mains du marché noir, certains ont été sollicités

(56) Entretien de Jacques Bourquin avec Jacques Seidel, op. cit. 
(57) Ibid.

(58) Ibid. par la milice, ils se sont aussi retrouvés dans la résistance d'où parfois leur arrestation. Ainsi, un jeune se retrouve placé jusqu’à 21 ans à Saint-Hilaire pour avoir volé un sac de charbon dans un dépôt de la SNCF, d'autres pour des vols de nourriture.

Pour les moniteurs-éducateurs, beaucoup n'avaient pas 20 ans en 1940, leur entrée dans la vie adulte s'est passée dans une période où être jeune était difficile, où les choix à faire étaient graves, parfois synonymes de rupture totale avec le milieu de vie : Résistance, STO. Beaucoup n’ont pas poursuivi d'études à cause de ce même STO. Ils ont vécu dans une totale insécurité, à l'image des jeunes dont ils allaient s'occuper, insécurité où pour se protéger il fallait parfois entrer dans une sorte de clandestinité. Pour les gosses comme pour les moniteurs-éducateurs, les IPES et les centres d'accueil pouvaient avoir, à partir de situations relativement voisines, une fonction de protection réelle.

Il y a proximité parce qu'il n'y a pas de frontière nette entre le délinquant et celui qui ne l'est pas. La délinquance des jeunes est à l'époque souvent économique, marché noir, trafic. Tout le monde y participe plus ou moins, c'est ce qu'on appelle le système $\mathrm{D}$. C'est à la fois une manière de survivre et de s'opposer à l'occupant. Un moniteur-éducateur dit : "Les gosses sont parfois arrivés au centre d'éducation surveillée pour des délits que nous avons nousmêmes commis. " ${ }^{(57)}$ L'illégalité est valorisée contre une autorité dont on pouvait contester la légitimité.

La proximité entre les moniteurs-éducateurs et les pupilles est renforcée par les archaïsmes de l'institution Éducation surveillée. Le quotidien de l'IPES est ponctué par un rituel lié au caractère obsessionnel de la surveillance entretenue par les moniteurs. Pour les jeunes comme pour la majorité des moniteurs-éducateurs, il y a un repoussoir commun : la Pénitentiaire concrétisée par les "gaffes " dont la majorité a mal accueilli les idées de réforme introduites dès 1938. À cela s'ajoute le poids hiérarchique où jeunes et moniteurs-éducateurs se vivent comme enfermés dans des soumissions si ce n'est égales au moins parallèles. "Nous étions comme des gosses sous surveillance... surveillance de l'éducateur-chef, lui-même sous celle du directeur, les faits et gestes de chacun d'entre nous, même notre vie privée, étaient observés. " ${ }^{(58)}$ Ceci est certes renforcé par une vie institutionnelle très fermée, coupée de l'extérieur, malgré les quelques tentatives d'ouverture faites par François Dhallenne 
à Saint-Hilaire ; l'extérieur immédiat reste hostile, dans les villages avoisinants, on continue à parler des colons et de la colonie pénitentiaire et lorsque François Dhallenne commence à établir quelques relations avec l'environnement, il ne le fera ni avec Roiffé ni avec Fontevrault, communes toutes proches dont les habitants ont depuis près d'un siècle comme seul rapport à «la colonie ", la prime que l'on venait toucher lorsqu'on ramenait un évadé.

- Le climat de complicité

L’ensemble des liens de proximité crée des complicités réelles entre les moniteurs-éducateurs et les " gosses ", complicité à peine nuancée par la présence des moniteurs-éducateurs d'avant 1939. La plupart de ceux-ci, dans la logique de la hiérarchie pénitentiaire restaurée en 1940, remplissent à cette époque des fonctions de type administratif (greffiers, comptables) ou travaillent en tant qu'adjoints du directeur, ils semblent éloignés des jeunes moniteurs-éducateurs arrivés en 1942-1943. Le quotidien du moniteur-éducateur, c'est le groupe, les "gosses ». Les complicités avec eux apparaissent sous toutes les formes. "Vous me permettez cela ?", disait un garçon à Jacques Seidel à Saint-Jodard, " mais on ne vous mettra pas dans la position d'être inculpé à votre tour. Un tel va se faire la malle, faites gaffe parce que vous allez avoir des ennuis. " ${ }^{(5)}$ Les complicités qui reposent sur une base de confiance, de reconnaissance réciproque enrichissent la rencontre entre les jeunes et les moniteurs-éducateurs. Elles sont renforcées, parce que les uns comme les autres se vivent comme en attente, pour les " gosses " celle de la mise en liberté, pour les moniteurs-éducateurs celle de la libération du territoire, car pour la majorité d'entre eux, il n'y a aucun doute, à la fin de la guerre, ils reviendront "à la vie civile ". On est dans le provisoire, comme l'exprime Joseph Villier. Au centre d'accueil des Tourelles en 1943, «la troisième année de l'occupation c'était l'année noire, c'était le coincé dans le coincé, on ne savait rien du lendemain, on vivait le temps présent le mieux possible avec les gosses qu'on apprennait à connaître. ${ }^{(60)}$ André Bernard, évoquant Saint-Hilaire, explique : «En 1943, nous n'avions pas de distractions, nous concentrions notre vie sur l'établissement, on vivait à l'heure de l'institution avec les jeunes et eux ne cherchaient pas à s'évader, il y avait la police allemande, les évènements nous rendaient proches. ${ }^{(61)}$

(59) Entretien de Jacques Bourquin avec Jacques Seidel, op. cit.

(60) Entretien de Jacques Bourquin avec Joseph Villier, op. cit.

(61) Entretien de Jacques Bourquin avec André Bernard, op. cit. 
(62) Entretien de Jacques Bourquin avec Jacques Seidel, op. cit.

\section{(63) Entretien de} Jacques Bourquin avec Joseph Villier, op. cit.

(64) Entretien de Jacques Bourquin avec Jacques Seidel, op. cit.

(65) Entretien de Jacques Bourquin avec Victor Ventré, $o p$. cit.

(66) Ibid.

(67) Entretien de Jacques Bourquin avec René Courtois, op. cit.
Cet épisode intense avec les jeunes s'accompagne de nouvelles activités à découvrir avec eux : une première veillée, une chorale, une nuit sous la tente (le scoutisme est tout proche). Jacques Seidel, à Saint-Jodard, début 1944 : " J'avais 20 ans, je vivais avec les mômes, on faisait des jeux de foulard, des baignades interdites, la pêche à la main, tout ce que les gosses aiment faire et qui est interdit... Plaisir de vivre, un jour je monte dans un clocher avec les gosses, on regarde le ciel, les Monts de la Madeleine, on parle de la nature, on est heureux. " ${ }^{(62)}$

Vivre avec : voilà le maître mot de la rééducation que les moniteurs-éducateurs sont en train de découvrir au contact des jeunes. "Derrière leur carapace, leur front buté, leur misère, les jeunes considérés longtemps comme tarés et pervers, expriment derrière leur apparente rudesse un besoin de chaleur, d'échange, de confiance qui ne peut être entendu que parce qu'il y a un réel partage avec eux dans tous les moments du quotidien. " "(63)

Jacques Seidel, à Saint-Jodard : "Il y avait la veillée après le repas dans une salle que l'on fermait à clé, un moment détendu, le groupe bien replié sur soi, avec moi au milieu, on jouait aux cartes, les gosses parlaient d'eux, j'ai découvert là plus que dans les dossiers leurs histoires, leurs misères. " ${ }^{(64)}$

Loin des théories pénitentiaires, médicales, pédagogiques, le moniteuréducateur est en train de construire avec les jeunes, sur un mode empirique, un quotidien plein de gratifications pour les uns comme pour les autres : les moniteurs-éducateurs sont séduits par ces gosses « qui ne s'aplatissent pas, qui ont une parole, du courage ".

Il est vrai que lorsque François Dhallenne est revenu de captivité fin 1941,Victor Ventré, son adjoint, dit : «On s'était débarrassé des plus fortes têtes, on avait fait la vidange... après cet écrémage, on a fait de l'éducation. " ${ }^{(65)}$

Cette incursion progressive des loisirs avec les jeunes va aider à changer le climat de l'institution. Le moniteur-éducateur est en train d'y trouver une place spécifique, différente de celle de l'instituteur dans sa classe et de l'instructeur dans son atelier.

À Saint-Hilaire, en 1943, on s'inspire du scoutisme jusqu'à y créer une troupe avec les jeunes. "Le scoutisme, dit Victor Ventré, c'est un moyen pour le jeune d'accepter les règles de la vie communautaire. " ${ }^{(66)}$

À Saint-Maurice, René Courtois ${ }^{(67)}$ évoque la création d'une "république » 
instituée aux sections de "mérite ", d' " honneur " et d' " excellence ", en janvier 1944, et dont le premier objectif sera de répartir également entre les jeunes les tickets de pain envoyés par les familles, de même que les allocations versées par la formation professionnelle. Faire que les jeunes ne se vivent plus comme des détenus, mais comme des citoyens.

«La république » de Saint-Maurice qui durera de longues années était constituée d'un gouvernement provisoire dont les membres étaient élus à l'issue de véritables élections.

Tout cela ne manquait pas de sel, au début 1944, où l'Éducation surveillée dépendait du secrétariat d'État au Maintien de l'Ordre et de la milice plutôt attirée par les fascismes que par un idéal républicain! Cette complicité, René Courtois la vivait profondément avec les pupilles en recevant des jeunes juifs auxquels il donnait une autre identité, mais aussi de jeunes résistants et des petites mains du marché noir avec lesquels il créa "la république ». C'était pour lui une complicité contre les occupants, contre un certain ordre moral et politique qui n'était pas le sien. Mais il poursuivait : «En 1945, les choses se stabilisaient, se structuraient, il allait falloir trouver d'autres complicités. » ${ }^{(68)}$

La complicité apparaissait donc dans ce contexte comme un élément dynamique, porteur de créativité mais aussi de limites, complicité des moniteurséducateurs avec les jeunes contre les séquelles encore lourdes de l'Administration pénitentiaire qui les enfermait les uns comme les autres dans des soumissions voisines, complicité d'un directeur avec les jeunes contre les occupants et le régime de l'époque.

Période tout à fait privilégiée dans la mesure où elle permettait pour la première fois que des jeunes placés à l'Éducation surveillée et ceux chargés de les rééduquer aient à mener ensemble des luttes, des conquêtes qui les réunissaient au lieu de les opposer.

\section{Les monitrices-éducatrices et les établissements de filles}

Ces établissements existent à l'Administration pénitentiaire depuis la fin du XIXème siècle sous l'appellation d'écoles de préservation. Ils ne sont jamais évoqués dans les campagnes de presse des années 1930, pourtant ces institutions, par la dureté de leur régime, ne cèdent rien aux colonies pénitentiaires des garçons. 
(69) Béatrice Koppel, Marguerite B., une jeune fille en maison de correction, Paris, Hachette, 1987, p. 121.

(70) Entretien de Béatrice Koppel avec Dominique Riehl, avril 1980 .
Ce sont des mondes secrets, ignorés des journalistes et de l'opinion publique. Aucune loi de réforme à partir de 1936 à l'égal de celles de SaintMaurice et de Saint-Hilaire.

Béatrice Koppel écrit dans Marguerite B., une jeune fille en maison de correction: "Ces trois établissements, Clermont de l'Oise, Doullens et Cadillac, trouvent dans les savoirs spécifiques des criminologues leur véritable justification... Le culte de la punition et de la discipline s'enlisant dans la répétition de gestes morbides en dehors du temps et des gestes du monde. » ${ }^{(69)}$

Pourtant, en 1939, le Dr André, dans un rapport sur l'école de Clermont, avait donné l'alerte concernant cette institution, mais ce fut sans suite. C'est seulement en 1942-1943 que le service de l'Éducation surveillée s'ouvre de ce problème au professeur Lagache qui intervient à Villejuif. Daniel Lagache demande, début 1944, à une de ses assistantes en psychologie, Dominique Riehl, qui a été avant la guerre directrice pédagogique d'un établissement célèbre de l'enfance « irrégulière » - l'établissement Oberlin en Alsace -, de bien vouloir "faire une visite de repérage " à l'école de préservation de Cadillac. ${ }^{(70)}$ Melle Riehl revient scandalisée, le service de l'Éducation surveillée lui demande de tenter une réforme, ce qu'elle refuse dans un premier temps.

Devant l'insistance de l'administration et plus particulièrement de l'inspecteur Paul Lutz, elle accepte cette tentative de réforme juste avant la Libération. On lui donne carte blanche pour recruter les premières monitrices-éducatrices et son adjointe. Elle choisira pour la seconder Geneviève Boutault, docteur en droit, qui a dirigé une école de formation sociale, puis six monitrices-éducatrices dont trois institutrices qui viennent de l'Éducation nationale, l'une a un certificat de psychologie et une autre le certificat d'aptitude à l'enseignement des enfants arriérés, deux titulaires de diplômes commerciaux et une dernière diplômée de l'école des cadres de la jeunesse.

Comme Mlles Riehl et Boutault, la majorité des arrivantes sont éclaireuses et ont une expérience des méthodes actives. On est assez éloigné du recrutement très empirique des moniteurs-éducateurs, il n'y a pas eu, pour les femmes, la menace du STO. Nous avons là une équipe cohérente qui inclut à la fois l'éducation, la scolarité, la formation professionnelle, les loisirs.

C'est sans difficulté qu'au moment de la Libération, l'Administration pénitentiaire se laissera déposséder du secteur des mineures. 


\section{Un essai de formation des moniteurs-éducateurs.}

La session Lagache à Clermont-Ferrand, novembre 1943

La session de formation, organisée à Fresnes en décembre 1936 pour les nouveaux moniteurs-éducateurs, n’a pas eu de suite.

L'afflux de ces personnels, à partir de 1942, repose au service de l'Éducation surveillée le problème de la formation. Pierre Ceccaldi fait appel à Daniel Lagache, qui intervient au centre d'accueil de Villejuif, il est professeur de psychologie à l'université de Strasbourg, replié à Clermont-Ferrand : c'est là qu'aura lieu une session d'une vingtaine de jours destinés aux moniteurs-éducateurs.

Daniel Lagache est assisté de deux psychologues, Dominique Riehl et Marianne Hossenlop.

Il ne s'agit plus comme en 1936 d'une session très liée aux pratiques pédagogiques du scoutisme et de l'éducation populaire mais d'une démarche beaucoup plus centrée sur la psychologie clinique. Daniel Lagache est proche de la psychanalyse. Joseph Villier, qui deviendra lui-même quelques années plus tard psychologue et psychanalyste, a participé à cette session. Il évoque le souvenir de ce stage : "Ce fut pour moi une véritable ouverture, une fenêtre grande ouverte sur une autre façon de penser était en train de s'ouvrir. " ${ }^{(1)}$

Lagache avait intitulé ses deux premières interventions ; "l'existence humaine est conflictuelle, débat de l'homme avec le monde et avec lui-même " et « la criminalité et la délinquance sont des inadaptations de l'individu à ses conflits".

Dans une dimension plus pédagogique, on insistait ensuite sur « la rééducation en cure libre ", la collaboration avec les familles, toutes ouvertures qui allaient à l'encontre d'une rééducation qui était en train de se construire autour du placement en internat, du retrait de la famille souvent perçue comme "mauvaise".

On était loin de l'univers des centres d'accueil et des premières IPES où intervenaient les moniteurs-éducateurs malgré les tentatives de scoutisme à Saint-Hilaire. La dimension pédagogique de la session privilégiait les méthodes actives, Decroly, le self government. Cette dernière approche, l'IPES de SaintMaurice, dès 1944, s'efforcera de l'inscrire dans la logique du système progressif souvent décrié, en créant un groupe, sans éducateur pour les plus anciens,

\author{
(71) Entretien de \\ Jacques Bourquin avec \\ Joseph Villier, op. cit.
}


(72) Entretien de Jacques Bourquin avec René Moret, juin 1980. on disait " groupe d'excellence », une voie vers l'autonomisation, disait-on, la réinsertion des jeunes!

\section{Les moniteurs-éducateurs qui sont restés après la guerre}

Il subsiste quelques dizaines de moniteurs-éducateurs au moment de la Libération, Saint-Hilaire sera presque vidée de son personnel éducatif.

Beaucoup d'entre eux avaient réellement pensé qu'après la guerre, ils rentreraient dans ce qu'ils appelaient " la vie active " pour reprendre leur profession, leurs études. Il n'y avait pas une idée de métier possible liée à cette expérience qui devait être sans lendemain.

L'idée de professionnalisation commençait à apparaître dans le secteur privé avec les premières écoles de cadres, comme on disait à l'époque, dans les services de l'Éducation surveillée, cette issue n'était pas perceptible.

Il y avait ceux qui n'avaient pas eu d'activités professionnelles avant 1943, si ce n'est des emplois provisoires, des études à peine entamées, et dont le statut d'éducateur de l'Éducation surveillée du 1er avril 1945, pouvait être un avenir possible. Un moniteur-éducateur exprime ainsi cette éventualité : "C'était trouver par l'Éducation surveillée un milieu protégé dans un travail et la sécurité de fonctionnaire... nous avions conscience d'avoir contribué à faire pencher la balance vers l'éducatif, il y avait quelque chose à construire dans ce domaine. " ${ }^{(72)}$

Apparaît dans ces entretiens, l'idée que l'on va se " reconstruire " après des années difficiles. Les moniteurs-éducateurs ont été très touchés par les blessures des enfants avec lesquels ils ont vécu cette longue parenthèse qu'ils ne referment pas.

\section{L'éducateur de l'Éducation surveillée}

\section{5-1952 : Une première génération}

L'ordonnance du 2 février 1945 sur l'enfance délinquante, dont les travaux préparatoires ont fait l'objet d'une commission de travail dans le cadre du gouvernement d'Alger dès 1943, consacre la notion "d'éducabilité du mineur délinquant ", dans la continuité des débats qui remontent à la fin du XIXème siècle. La mesure pénale, est-il mentionné, « n'est plus qu'une dérogation à titre exceptionnel et par décision motivée ». 
Un pas semble avoir été franchi. On met fin à l'ambiguïté entre la peine et la mesure éducative, la peine relève de l'Administration pénitentiaire, la mesure éducative de l'Éducation surveillée.

Le 21 février 1945, Alice Delaunay, résistante, députée à l'Assemblée constituante provisoire, fait, à l'occasion du débat sur le budget de la Justice, une longue intervention sur l'urgence qu'il y a à créer une direction de l'Éducation surveillée autonome de l'Administration pénitentiaire. Elle a visité auparavant et à plusieurs reprises l'IPES de Saint-Maurice, dont elle fait l'éloge de la réforme en cours, elle insiste aussi sur la nécessité qu'il y a à " créer un institut de formation pour les nouveaux personnels de l'Éducation surveillée : instituteurs, éducateurs, moniteurs d'éducation physique, qui se destinent à l'éducation des enfants délinquants ".

\section{Le décret du 10 avril 1945 : le statut}

Ce décret, qui crée le statut des personnels de l'Éducation surveillée, dont celui de l'éducateur, s'inscrit pleinement dans les orientations de l'ordonnance du 2 février 1945. Il précède de quelques mois la création d'une direction de l'Éducation surveillée qui ne verra le jour que le 1er septembre 1945. Ce décret a été très soutenu par le directeur de l'Administration pénitentiaire de 1945, Paul Amor. Le décret du 10 avril reprend les idées développées dès 1937-1938, ainsi que le projet de 1941 de l'inspecteur Jean Bancal.

Le statut prépare la coupure institutionnelle entre les deux directions dont l'une est encore en gestation. C'est l'application d'une différence absolue entre le cadre des personnels de l'Administration pénitentiaire et celui de l'éducation surveillée dont on affirme la vocation éducative.

Concrètement, les choses sont difficiles à organiser dans un délai trop bref. Le chapitre 8 du décret prévoit des dispositions transitoires en envisageant la création d'une commission de reclassement des personnels dont la mission sera de répartir nominativement tous les fonctionnaires en activité, soit dans les services extérieurs de l'Administration pénitentiaire, soit dans ceux de l'Éducation surveillée. Il s'agira dans ce choix, précise le statut, de " tenir compte des aptitudes particulières dont chaque agent fait preuve jusqu’à présent et du désir exprimé par lui ».

Les éducateurs qui bénéficient d'un statut, existent à peine dans la réalité, 
la profession est à naître et l'Éducation surveillée aura bien du mal à la recruter dans un premier temps.

Conscients de cette difficulté, les rédacteurs du statut prévoient « qu'un fonctionnaire pourra être laissé provisoirement pour une durée qui ne pourra excéder deux ans dans un cadre autre que celui qui lui est affecté ».

La commission de reclassement se réunira en novembre-décembre 1945, elle examinera 496 dossiers de personnels pénitentiaires souhaitant être rattachés à l'Éducation surveillée, on en retiendra 238, le plus souvent des personnels moniteurs, moniteurs-éducateurs, qui ont fait preuve de leur intérêt pour des pratiques éducatives à l'égard des mineurs. Le nombre étant insuffisant, la commission ajoutera 160 personnels, maintenus provisoirement pour des raisons d'effectif. Le décret prévoyait leur maintien pour deux ans, les derniers ne quitteront l'Éducation surveillée qu'en 1951.

Ce statut prévoit un cadre éducateur qui inclut les fonctions de directeur et sous-directeur.

Dans l'Administration pénitentiaire, ces responsables relevaient du cadre administratif. La conséquence de ce choix est que seuls les personnels éducatifs peuvent accéder aux fonctions de direction. C'est un véritable pari quant à l'évolution de la fonction éducative qui est à construire. C'est bien autour d'elle que se crée la nouvelle identité de l'Éducation surveillée. Les enseignants professionnels en sont exclus, ce qui peut étonner car c'est sur eux qu'ont reposé les tentatives de réforme depuis 1938 et la formation professionnelle apparaît, au lendemain de la guerre, comme l'outil premier de la rééducation dans les IPES. Il y a vraisemblablement le souci de la part du législateur de ne pas limiter la rééducation à l'unique formation professionnelle.

Le principe du recrutement des nouveaux éducateurs est celui du concours, les candidats devront être titulaires du baccalauréat ou du brevet supérieur, à l'égal des instituteurs, pour l'emploi d'éducateur adjoint, premier grade de la fonction éducative. Il est prévu à l'article 8 que les candidats qui ont obtenu des diplômes ou effectué des stages les préparant à leur mission éducative, peuvent bénéficier d'une majoration de points ou être admis à concourir en n'étant titulaire que du certificat d'études ou du brevet élémentaire. Par ce biais, l'Éducation surveillée, à la recherche de candidats, réduit ses exigences de diplômes tout en essayant de recruter des personnels 
bacheliers ou non, ayant bénéficié de la formation dans les écoles de cadres du secteur privé, ouvertes en 1942-1943.

Par contre, les titulaires d'un diplôme d'enseignement supérieur pourront être recrutés comme éducateurs- chefs, il y en aura quelques-uns, ce sera aussi le moyen de recruter les premiers psychologues des centres d'observation dans un statut d'éducateur.

À remarquer qu'on accorde une place privilégiée au professeur d'éducation physique, recruté avec la deuxième partie du certificat d'aptitude au professorat d'éducation physique, ils occupent dans la hiérarchie une place entre les éducateurs-chefs et les sous-directeurs.

Il y a toutefois une réelle lacune dans le statut, aucune formation n'est prévue par la nouvelle direction. Paul Lutz laisse entendre qu'en 1945, la priorité était à la réforme des établissements et que les lignes budgétaires ne permettaient pas d'envisager la création d'un centre de formation. Comptait-on sur les écoles de cadres du secteur privé dont quelques éducateurs de l'Éducation surveillée venaient de sortir ?

Le premier concours d'éducateur de l'Éducation surveillée ne fut, pour des raisons budgétaires, organisé qu'en 1951. Ce qui était apparu important en 1945, c'était tout d'abord d'inscrire l'éducateur dans un statut de la Fonction publique.

En attendant le premier concours, l'Éducation surveillée s'efforça de solliciter le détachement d'instituteurs de l'Éducation nationale. Ils furent peu nombreux, beaucoup repartirent vite, ceux qui restèrent furent assez rapidement nommés éducateurs-chefs, puis sous-directeurs.

Jusqu'en 1950, le recrutement se faisait en référence au statut, dans chaque établissement, à partir d'un stage d'un mois. Au bout de quelques jours de stage, plus de la moitié des candidats repartait d'elle-même. Ceux qui restaient, plusieurs nous l'ont raconté, " mettaient plus de huit jours à défaire leur valise ». Le premier contact avec les institutions était souvent peu encourageant, l'un d'eux nous raconte son arrivée au CO de Savigny : " J'ai encore le souvenir de la manière dont j'ai eu à décliner mon identité, mes références, mes qualités, cela tenait plus du registre d'écrou que d'une attitude d'accueil. » ${ }^{(73)}$

Et pourtant, le CO de Savigny, qui venait d'ouvrir, n’avait pas de passé pénitentiaire!

(73) Entretien de Jacques Bourquin avec Jacques Selosse, mai 1980, Bulletin de psychologie, $\mathrm{n}^{\circ}$ 441, mai-juin 1999. 
(74) Fonds Brisset, versement $n^{\circ} 20000111$, Centre des archives contemporaines, Fontainebleau.
Après un mois, le candidat était accepté ou refusé et le ministère prenait sa décision suite au rapport du directeur. Reconnu apte, il était nommé éducateur adjoint et titularisé au bout d'un an, si les choses se passaient bien.

Le stage tenait beaucoup de l'auto-sélection et c'était environ un stagiaire sur six qui était retenu. Cette auto-sélection n'excluait pas la sélection par les jeunes qui à leur manière savait reconnaître un bon éducateur. Nous avons retrouvé le questionnaire que François Dhallenne ${ }^{(74)}$ faisait parvenir, courant 1945, aux candidats à un poste d'éducateur à Saint-Hilaire :

- Vous êtes-vous occupé d'enfants?

- Les aimez-vous?

- Avez-vous de l'autorité ?

- Pratiquez-vous le scoutisme?

- À quel titre?

- Connaissez-vous les méthodes du scoutisme?

- Avez-vous fait du camping?

- Faites-vous partie d'un mouvement de jeunesse?

- Avez-vous fait de l'orientation professionnelle?

- Avez-vous des connaissances en psychologie, en pédagogie ?

- Avez-vous des aptitudes reconnues pour :

* l'observation

* l'organisation de la vie d'un groupe

* le chant, le dessin, les arts d'agréments

* l'organisation des loisirs

* les sports

* l'enseignement

- Êtes-vous titulaire du CAP de l'enseignement des enfants arriérés ?

- Avez-vous des notions de droit, sciences pénales, administration, comptabilité ?

- Avez-vous des aptitudes non mentionnées ici ?

- Indiquez vos diplômes

- Quelle est votre religion? La pratiquez-vous?

- Joignez une photo.

Ce document exprime bien toutes les attentes d'un directeur d'IPES à l'égard de l'éducateur : quelqu'un qui puisse intervenir aussi bien dans le domaine sco- 
laire que dans le domaine des loisirs, de l'orientation, du sport ou même de l'administration. Les références à la religion sont plus liées à la personnalité du directeur qu'à l'institution qui est laïque, mais qui conservera des aumôniers rémunérés jusque dans les années 1960.

\section{Construire l'Éducation surveillée et l'éducateur}

La création de l'Éducation surveillée en tant que direction autonome de l'Administration pénitentiaire était à la fois le résultat d'un long aboutissement des réformes institutionnelles mais aussi une rupture voulue avec l'Administration pénitentiaire.

Le premier directeur, Jean-Louis Costa, nommé le ler novembre 1945, explique, dans un entretien en juin 1980, que la création d'une direction à vocation éducative dans le cadre du ministère de la Justice, n'était pas une mince affaire. "Elle faillit même partir à la Santé, en 1946, le garde des Sceaux et le ministre de la Santé y étaient favorables, j'ai dû m’y opposer en remettant ma démission si cela se réalisait. " ${ }^{(75)}$ L'important était d'être accepté par les magistrats et par les juges des enfants qui étaient eux-mêmes des nouveaux venus.

La nouvelle direction, avant même l'arrivée de Jean-Louis Costa, rédige le 25 octobre 1945 un règlement provisoire des centres d'observation et des IPES que Paul Lutz évoque dans un entretien de 1981 : "Ces textes étaient volontairement provisoires, ce qui signifiait qu'il ne fallait pas trop les prendre en compte, en fait c'est la réalité éducative qui devait l'emporter sur les textes. Ils étaient surtout nécessaires sur le plan administratif, budgétaire... en 1945, tout était possible. » ${ }^{(76)} \mathrm{Il}$ fallait construire, inventer.

- Les établissements

La direction de l'Éducation surveillée dispose en 1945 de :

- deux IPES en cours de réforme (Saint-Maurice et Saint-Hilaire) ;

- deux autres IPES non réformées, Belle-Île et Aniane, on donne à cette dernière le statut d'institution d'éducation corrective, elle conserve un quartier pour mineurs condamnés et criminels ;

- l'IPES de Saint-Jodard, ouverte en 1943, dans les Monts du Forez ;

- Neufchâteau, une ancienne caserne de dragons, dont l'armée vient de se
(75) Entretien de Jacqueline Costa-Lascoux avec Jean-Louis Costa, juin 1980.

(76) Entretien de Jacques Bourquin avec Paul Lutz, op. cit. 
dessaisir ;

- un établissement pour mineurs de 13 ans, à Chanteloup, près de SaintHilaire, qui existe depuis le début du siècle ;

- un établissement de filles à Cadillac, ancienne école de préservation dont on tente la réforme ;

- un centre d'observation à Savigny, près de Paris, qui va progressivement regrouper, entre 1946 et 1950, les anciens centres d'accueil de la région parisienne.

Un patrimoine qui a un lourd passé pénitentiaire ; seuls Saint-Jodard, Neufchâteau et Savigny y échappent.

- Quels cadres pour diriger ces établissements?

À Saint-Hilaire et à Saint-Maurice, ce sont les réformateurs de 1938 qui conservent leurs responsabilités : François Dhallenne et René Courtois. Lorsque, fin 1945, François Dhallenne recevra la direction du nouveau CO de Savigny, il est remplacé à Saint-Hilaire par un de ses adjoints, Victor Ventré, qui avait été recruté comme moniteur-éducateur en 1937.

On nommera à la tête de Saint-Jodard, Raymond Pailhes, lui-même recruté dans le cadre des réformes de Saint-Hilaire en 1937.

C'est Jacques Ceccaldi, ancien officier directeur du camp de forestage de Marlotte en 1943-1944, qui prend en 1945 la direction de la nouvelle IPES de Neufchâteau, un établissement sans passé pénitentiaire auquel il donnera un style assez militaire.

Pour les autres établissements, l'Éducation surveillée, consciente de la nécessité de faire appel à des cadres extérieurs, recrute Guy Sinoir, psychologue et spécialiste de l'orientation professionnelle, auquel on donne, en mai 1945, la direction du nouveau centre d'observation de Savigny-sur-Orge. Dès fin 1945, la direction de l'ES proposera à Guy Sinoir de devenir son conseiller pour les problèmes de psychologie et d'observation, poste qu'il gardera vingt-cinq ans, où il aura un rôle important dans l'évolution de l'Éducation surveillée.

Pour réformer l'institution de Chanteloup, la direction, influencée par Henri Michard, fait appel à un couple d'enseignants de l'Éducation nationale, M. et Mme Vincendon, disciples du pédagogue Adolphe Ferrière et militants des méthodes actives, ils ont dirigé des établissements pour enfants " arriérés ». 
Un projet qui soulèvera beaucoup d'espoir jusqu'au départ des Vincendon en 1951. L'Éducation surveillée n'était pas encore prête à tant d'ouverture et elle mit fin à leur mission.

Concernant l'unique établissement de filles, Cadillac, l'Éducation surveillée avait fait appel, en 1943, à Mlle Riehl, une psychologue. Après beaucoup de réticences, elle accepta, courant 1944, de tenter la réforme.

Ces responsables auront un rôle essentiel dans le recrutement des éducateurs et jusqu'à l'organisation du 1er concours en 1951, cette sélection reposait uniquement sur eux.

René Courtois écrit le 12 septembre 1944 au sous-directeur de l'Éducation surveillée, Pierre Ceccaldi : "Il nous faut trouver des hommes capables, ardents, réalisateurs, préoccupés avant tout de l'intérêt des jeunes beaucoup plus que de leurs soucis égoïstes et familiaux. " (77) Une manière de préférer les célibataires, sans que ce soit une exigence absolue comme ce fut le cas pour les éducatrices.

Paul Lutz, au cours d'une inspection à Neufchâteau, ${ }^{(78)}$ en 1949 , porte un regard positif sur ces nouveaux personnels : "Le personnel éducateur a une claire conception de sa mission éducative et s'y adonne avec foi et compétence. Il est bien choisi et prend sa tâche à cœur. " Décrivant les activités dont ils sont les acteurs : "Ils sont proches des mineurs, acceptent de vivre avec eux à table, en promenade, ils maintiennent les exigences de la discipline, pas de familiarité de mauvais aloi, des déplacements en rang, au pas. Ils ont été bien choisis, sont animés de servir la cause de l'enfance et donnent le meilleur exemple à leurs pupilles. »

Jean-Louis Costa publie en avril 1946 un document d'une centaine de pages intitulé Plan de réforme des services de l'Éducation surveillée et des institutions protectrices de l'enfance en danger moral. C'est un plan quinquennal qui prévoit les réformes et les objectifs à atteindre autant dans le secteur public que dans le secteur privé de la rééducation. Dans le chapitre concernant les institutions, est évoquée la question des personnels et plus particulièrement, la nécessité de : "Éliminer au plus vite les personnels pénitentiaires non affectés à l'Éducation surveillée par la commission de réforme de 1945 , ils sont encore 144 en avril 1946. " Et l'inconvénient de "l'absence d'école de cadre pour la formation théorique des éducateurs " que l'on qualifie dans ce
(77) Fonds René

Courtois, Conservatoire des archives de la protection de l'enfance et de l'adolescence, Archives du monde du travail, Roubaix.

(78) Paul Lutz, Rapport d'inspection sur l'IPES de Neufchâteau, 14 février 1949, document consulté à la bibliothèque $2 \mathrm{RJ}$, CNFE-PJJ, Vaucresson. 
(79) Projet pour un centre de formation et d'études de l'Éducation surveillée, Fonds Brisset, versement $n^{\circ} 20000111$, Centre des archives contemporaines, Fontainebleau.

(80) In revue Rééducation, $\mathrm{n}^{\circ} 17$ et 18 , juillet et novembre 1949. document d'éducateurs spécialisés.

Le plan prévoit, en attendant la création d'une école, « des liens avec les écoles des ARSEA, ouvertes à la fin de la guerre, et l'école de Beaumont-surOise qui dépend de l'Éducation nationale où elle forme des instituteurs spécialisés au certificat d'aptitude à l'enseignement des enfants arriérés devenus depuis 1945 des enfants inadaptés ».

Henri Michard, chargé, dès 1945, par la sous-direction puis la direction de l'Éducation surveillée, de préparer la création d'un centre de formation et d'études, en pose très vite les premières bases : «Il s'agit, écrit-il, d'établir un lien étroit entre la formation et la recherche, un moyen essentiel pour inventer l'Éducation surveillée et de nouvelles méthodes. " ${ }^{(79)} \mathrm{Il}$ pense, dans un premier temps, que le centre doit s'occuper de la formation de perfectionnement, la formation initiale des éducateurs devant revenir à l'Éducation nationale et plus particulièrement à l'école de Beaumont. Il souhaite que celle-ci ouvre une section pour l'enfance délinquante. Mais à la suite de plusieurs inspections à SaintHilaire et Saint-Maurice, il revient sur cette position : "L'éducateur n'a pas la même mission que l'instituteur, les enfants délinquants sont différents des enfants arriérés. "

Pour Henri Michard, comme pour l'équipe de direction de l'Éducation surveillée (Jean-Louis Costa, Pierre Ceccaldi, Paul Lutz, Guy Sinoir), la formation est l'outil premier de la réforme, elle doit aider, avec la recherche, à dégager, à exposer la doctrine de l'Éducation surveillée.

Le débat sur la formation, sur la mission de l'éducateur préoccupe tout autant le secteur public que le secteur privé habilité Justice. Guy Sinoir et Henri Joubrel débattent sur la nécessité qu'il y a ou non d'être bachelier pour être éducateur : "Ne va-t-on pas privilégier la théorie au détriment du cour. » ${ }^{(80)}$

Être éducateur, n'est-ce pas une mission morale, comme l'évoquait déjà Paul Cuche, au début du siècle, qui repose plus sur la vocation, le dévouement, la qualité de l'engagement ?

$\mathrm{Y}$ aurait-il une tendance empirique qui s'opposerait à une tendance intellectuelle? Le Dr Le Guillant, psychiatre, responsable en 1947 du secteur de l'enfance inadaptée au ministère de la Santé, n'oppose pas les deux approches, elles sont complémentaires. "Il doit y avoir, écrit-il, un compromis nécessaire entre vocation et technicité, ce sont deux nécessités inséparables, l'acquisi- 
tion autant que possible de connaissances théoriques et pratiques, qui, si incertaines soient-elles, sont indispensables à une compréhension véritable des enfants inadaptés. " ${ }^{(81)}$

Les jeunes délinquants sont inscrits, à cette époque et jusque dans les années 1970, dans le secteur de l'enfance inadaptée et considérés comme tels aussi bien par les médecins que par les magistrats pour enfants. Le Dr Le Guillant pense qu’à l'image des internes en médecine, la formation des éducateurs doit se faire dans " un internat-école » où psychologues, médecins, éducateurs, enseignants, tout en remplissant leur fonction dans l'institution, ont un rôle d'enseignant auprès des jeunes éducateurs. "C'est la théorie qui se dégage de la pratique. " ${ }^{\left({ }^{22}\right)}$ Henri Michard ne fera pas ce choix pour l'Éducation surveillée. Dans un congrès de l'UNAR (Union nationale des associations régionales) de 1950, il évoque le futur projet du centre de formation et d'études de l'Éducation surveillée : "Plus qu'un enseignement didactique, ce sera une réflexion sur les problèmes pédagogiques posés par la rééducation, une préparation à les résoudre d'une manière vivante et personnelle, une préparation à participer à des travaux de recherche qui se poursuivront dans nos établissements. " ${ }^{(83)} \mathrm{Il}$ envisage, à partir de ce projet, une année théorique qui précède la formation pratique, en prévoyant la mise en place d'une recherche-action avec le lieu de pratique.

Un projet qui prend bien en considération le fait qu'il s'agit de préparer les gens à une profession aux contours encore incertains, sans se laisser modéliser par une pratique institutionnelle qu'il faut faire évoluer et dégager de la référence pénitentiaire. C'est ce modèle de formation qui se mettra en place lors de l'ouverture du centre de formation et d'études de Vaucresson à partir de 1952. En attendant, la formation des éducateurs de l'Éducation surveillée se limitera à une ou deux sessions annuelles de trois semaines.

- Les sessions de formation, 1947-1950. «La formation missionnaire "

Les deux premières sessions, au contenu quasi-identique, vont se dérouler au centre d'observation de Savigny en novembre 1947, et en décembre 1948 à l'Institut national d'éducation populaire à Marly-le-Roi. Il y a une vingtaine de participants par session.

Dans son introduction aux stages de Savigny, Jean-Louis Costa, directeur de l'Éducation surveillée, présente ainsi le projet : "L'Éducation surveillée
(81) Louis Le Guillant

et Simone Hénaff,

Sauvegarde, $\mathrm{n}^{\circ} 2,1951$.

(82) Ibid

(83) Henri Michard, «Allocution de M. Michard ", Sauvegarde de l'enfance, $\mathrm{n}^{\circ} 2-3$, février-mars 1951. 
(84) Jean-Louis Costa, Session de formation de Savigny-sur-Orge, 1947, document consulté à la bibliothèque 2RJ, CNFEPJJ, Vaucresson.

(85) Entretien de Jacques Bourquin et Vincent Peyre avec Henri Michard, novembre 1995. constitue un groupe d'hommes [il y a deux stagiaires femmes], chargés de mettre en œuvre une idée commune. Il s'agit de préciser cette idée, d'analyser les critiques, de mettre au point les moyens dont on dispose. " ${ }^{(84)} \mathrm{On}$ est bien dans une logique de construction, d'inventaire, le passé pénitentiaire encore si proche n'est pas une référence. Il poursuit, en souhaitant « qu'une fois rentrés dans leurs établissements, les éducateurs prolongent les effets du stage en diffusant parmi leurs collègues les enseignements qu'ils auront acquis. Que les éducateurs soient les ferments de ces sessions ». C'est ce qu'Henri Michard appellera « la formation missionnaire ».

Arrêtons-nous un peu sur les contenus et les intervenants de ces sessions sur lesquels tant d'espoirs sont fondés. Au niveau des contenus, il s'agit surtout d'apports didactiques qui incluent des références médicales et psychologiques, où l'importance est apportée à la biologie et à la neuropsychiatrie infantile, un aspect plus pédagogique à partir des méthodes éducatives, de l'observation, de la rééducation, du rôle de l'éducateur, puis tout un champ relatif au droit, à la criminologie et à l'administration. Comme le soulignera plus tard Henri Michard, « la sociologie n'a pas encore droit de cité et les mécanismes de l'inadaptation sont à peine abordés ». ${ }^{(85)}$

Concernant les intervenants, le Dr Bize, que l'Éducation surveillée vient de recruter en tant que médecin conseil de la direction, est un neuropsychiatre, spécialiste de bio-typologie et d'orientation professionnelle. Il imprègne fortement les premières pratiques d'observation à l'Éducation surveillée vers un projet de classification très médicalisant et comportementaliste des mineurs délinquants, ce qui le situe dans un registre très différent de celui que le Pr Lagache avait introduit lors de la session, en 1943, à Clermont-Ferrand. Interviennent aussi dans ce champ médical : le Dr Georges Heuyer, fondateur de la neuropsychiatrie infantile pendant l'entre-deux guerres, il a une grande influence sur les orientations du secteur de l'enfance inadaptée en train de se constituer dans le secteur privé, ses travaux sur l'enfant délinquant font autorité, le philosophe R. Le Senne, professeur au Collège de France, parle de la caractérologie sur laquelle il vient de publier un traité qui a une grande audience. On est toujours dans le souci de classification.

Guy Dutey, jeune éducateur, qui deviendra, au début des années 1950, directeur du centre d'observation de Lyon, évoque le poids de la caractérologie dans 
l'enseignement reçu au cours de la session : «L'intervention de Le Senne était l'élément dominant, on distinguait les émotifs, les non-émotifs, les actifs, les non-actifs, les primaires, les secondaires, très vite je me rendis compte que ce n'était d'aucune utilité. " ${ }^{(86)}$

L'apport de Guy Sinoir introduisant la psychologie des conflits était très minoré. La référence pédagogique était celle qui s’appliquait à l'égard des enfants arriérés, l'assimilation entre délinquance juvénile et arriération restait très forte.

Enfin, il y avait des conférences par des spécialistes de la pédagogie scolaire, sportive, des activités dirigées dans les IPES, ce qui amenait certains directeurs d'institutions (Dhallenne, Riehl) à parler de "leur maison ». On évoquait aussi les pratiques du secteur privé avec Henri Joubrel, un des promoteurs du métier d'éducateur dans ce secteur, et Jean Pinaud, qui avait ouvert, fin 1943, l'école d'éducateurs de Montesson, près de Paris.

Deux magistrats pour enfants (Jean Chazal et Jean Coxtet de Andréis) abordaient la législation de la protection de l'enfance et les membres de l'équipe dirigeante de l'Éducation surveillée présentaient les cadres judiciaires et institutionnels de la nouvelle direction. C'était aussi un moyen pour eux de rencontrer ces jeunes éducateurs.

Dans ce programme, nous ferons une place à part à deux interventions : celle de François Dhallenne sur l'éducateur, et celle de Dominique Riehl sur l'éducatrice.

Évoquant l'éducateur, François Dhallenne a un propos très métaphorique : «Un jour, le bon jardinier arrive, l'arbuste est encore jeune, il ne produit rien sauf des épines, on peut comparer le jeune délinquant au sauvageon qui a grandi dans un jardin et qui produit de mauvaises épines. [...] Comme le bon jardinier, l'éducateur de jeunes délinquants arrive, il doit émonder, greffer s'il y a lieu, tailler, conduire, et ce par la seule influence de sa volonté. Les fruits qui constitueront sa récompense seront dans l'amendement obtenu et le reclassement social du sujet dont il aura obtenu le sauvetage. " ${ }^{(87)}$ Sauvageon, reclassement, sauvetage, des mots que l'on trouve dans beaucoup d'articles de l'époque.

Puis, dans un registre plus concret, François Dhallenne évoque l'éducateur idéal : "Il est grand, robuste, souple, viril, bouillant d'énergie, franc, loyal, travailleur, opiniâtre, chercheur, sympathique, en un mot il n'existe pas tout
(86) Guy Dutey, Pour

l'Histoire, Bulletin de l'AHES-PJM, n 38, avril 2005 .

(87) François

Dhallenne, Session de Savigny-sur-Orge, 1947, document consulté à la bibliothèque 2RJ, CNFEPJJ, Vaucresson. 
(88) Dominique Riehl,

Session de Savigny-sur-

Orge, 1947, document consulté à la bibliothèque 2RJ, CNFE-PJJ,

Vaucresson. en espérant qu'à nous tous, nous arriverons à en fournir un. " L'idéal scout est là, sous-jacent, avec la nécessité du travail en équipe !

Avec Dominique Riehl, qui vient d'ouvrir l'IPES pour filles de Brécourt, en 1947, après avoir tenté en vain la réforme de Cadillac, nous ne sommes plus dans la métaphore, c'est une réalité plus sombre où pour les jeunes filles domine la référence à la sexualité : "Le malheur de nos pupilles a son origine dans les relations sexuelles, le viol, l'inceste, les liaisons amoureuses, la prostitution... L'éducatrice, dans un internat de filles, a trois tâches essentielles : prouver qu'il n'est pas nécessaire d'avoir des relations sexuelles avant ou en dehors du mariage, les détourner de la prostitution, les préparer à leur rôle de maîtresse de maison, d'épouse et de mère. L'éducatrice remplace la mère de famille, elle est responsable de la rééducation morale, sociale et familiale d'un groupe de huit filles. Elle doit avoir des sentiments moraux supérieurs, une conduite irréprochable, elle est un exemple, elle doit avoir une personnalité de chef, elle ne peut être mariée car elle ne peut s'occuper de son groupe de filles avec lequel elle vit et d'une famille à elle. " ${ }^{(88)}$

On est dans le dévouement total, dans l'abnégation, un modèle qui s'apparente, malgré la référence laïque, à celui des religieuses des Refuges et du Bon Pasteur. Dominique Riehl poursuit : «Seule une jeune éducatrice agréable, plaisante, sinon jolie, qui pourrait avoir un mari ou, selon la morale des filles, avoir une liaison amoureuse, qui sans avoir des airs penchés ou mystiques mène une vie exemplaire tout en étant calme, pondérée, équilibrée, de bonne humeur et heureuse, a suffisamment de poids pour affirmer par une preuve vivante qu'en dehors du mariage, les relations sexuelles ne sont nullement nécessaires, ni souhaitables ni recommandables!»

Mesdemoiselles Riehl et Boutault, toutes deux célibataires, dirigèrent Brécourt pendant plus de vingt ans. En règle générale, les éducatrices y restèrent beaucoup moins longtemps que les pupilles.

Le contenu de la session de Marly, en 1948, ne differera guère des précédentes, avec toutefois ce changement, elle ne se déroule plus au centre d'observation de Savigny mais à l'Institut national d'éducation populaire de Marly-le-Roi. Le choix du site n'est pas indifférent, les liens entre la direction de l'Éducation surveillée et l'Éducation populaire vont se développer grâce à Henri Michard. 
Les éducateurs, qui pratiquent de longues années en internat avec les jeunes dont ils partagent la vie, ont besoin d'être initiés à de nouveaux outils pédagogiques introduits par le scoutisme mais qui doivent être développés, on parle d'activités médiatrices : le chant choral, le théâtre, les arts plastiques, le ciné-club. C'est cette rencontre avec les techniques de l'éducation populaire qui va enrichir le lien entre les éducateurs et les jeunes, dans une logique de " vivre avec » et du " faire avec ».

Un éducateur de ce stage nous dit : "C'est à partir de 1947-1948, que j’ai suivi des stages de reliure, de bibliothèque, d'entraînement mental proposé par Peuple et Culture très lié à l'Éducation surveillée. À Saint-Jodard, j’étais chanteur à la chorale, comédien dans la troupe théâtrale, c'était la belle vie ! " ${ }^{(89)}$

Dans son rapport sur l'IPES de Neufchâteau du 14 février 1949, Paul Lutz évoque très favorablement les éducateurs qui investissent " avec ardeur " les activités de loisirs avec les jeunes : "C'est la première fois que je vois dans une maison de garçons les mineurs réellement intéressés. Jusqu'alors j’avais plutôt l'impression qu'ils assistaient aux activités plus qu'ils n'y participaient. À Neufchâteau, les activités dirigées deviennent un exercice spontané, désiré, ceci découle de l'enthousiasme des éducateurs pour ce type d'activité et de leur gamme très diversifiée. " ${ }^{(90)}$

Henri Michard, dans une inspection à Saint-Jodard le 20 août 1949, montre son intérêt pour l'activité d'un " journal parlé » dans l'institution et d'une activité toute nouvelle de " vol à voile ». ${ }^{(91)}$

\section{Éléments personnels concernant les éducateurs du statut de 1945}

Nous avons constitué ce profil à partir de quelques dossiers d'admission et d'éléments recueillis dans le cadre de l'inscription pour les stages de 1947 à $1950 .{ }^{(92)}$

Le recrutement régional reste la règle comme pendant la guerre, il s'atténuera au moment du premier concours en 1951.

Sur les 93 stagiaires qui ont participé aux sessions organisées à Savigny puis à Marly, 72 ont été recrutés à partir du statut d'avril 1945, les autres sont des moniteurs-éducateurs recrutés pendant la guerre, des éducateurs et des cadres du secteur privé en 1948-1949.
(89) Guy Dutey, op. cit.

(90) Paul Lutz, Rapport d'inspection sur l'IPES de Neufchâteau, février 1949, document consulté à la bibliothèque $2 \mathrm{RJ}$, CNFE-PJJ, Vaucresson.

(91) Henri Michard, Rapport d'inspection sur l'IPES de Saint-Jodard, août 1949, document consulté à la bibliothèque 2RJ, CNFE-PJJ,

Vaucresson.

(92) Fiches d'évaluation d'éducateurs rédigées par Henri Michard, versement aux Archives nationales en cours. 
(93) Guy Dutey, op. cit.

- Le niveau d'instruction

Sur les 72, l'immense majorité est titulaire du baccalauréat ou du brevet supérieur, en référence au statut. Seuls 5 n'ont que le brevet élémentaire ou un certificat d'études accompagné d'un CAP d'ajusteur pour l'un d'entre eux. 8 sont titulaires d'une licence de droit ou de lettres, pour la moitié il s'agit de stagiaires femmes recrutées par Mlle Riehl. 3 hommes ont le CAP d'instituteur, 2 femmes le CAP d'institutrice, 1 éducateur a suivi la formation de l'école d'éducateur de Montesson. À signaler, un instituteur détaché de l'Éducation nationale qui ne restera pas, son cas n'est pas unique. À remarquer que le niveau des éducatrices recrutées par Mlle Riehl est souvent supérieur à celui de baccalauréat, c'est moins le cas chez les éducateurs.

- L'âge

$\mathrm{Au}$ moment du recrutement, il est environ de 27 ans pour les hommes, 23 ans pour les femmes. Plus de la moitié des hommes est mariée, avec au moins un enfant, les femmes sont toutes célibataires.

L'âge relativement important des hommes s'explique par les vicissitudes de la période de la guerre : 6 ont été prisonniers de guerre, 2 ont connu le STO en Allemagne, 2 ont été réfractaires et sont entrés dans la résistance, 8 se sont engagés dans l'armée de la Libération pour une durée de 2-3 ans, 7 signalent avoir été dans les chantiers de jeunesse dont 3 étaient cadres ou dans une école de formation de cadres. Tous ne connaissaient pas « la planque " de l'Éducation surveillée concernant le STO dont beaucoup étaient menacés.

L'un d'entre eux évoque sa rencontre avec l'Éducation surveillée, en 1946 : " Je vivais à Saint-Étienne, le journal local faisait savoir, dans ses offres d'emploi, que l'institution de Saint-Jodard recrutait du personnel. Excellente idée pour un chômeur décidé à faire n'importe quoi pour gagner sa vie. J'avais été chef de groupe aux chantiers de jeunesse avec des jeunes en difficulté physique, puis quelque temps rédacteur auxiliaire à la Préfecture, je me présentais. » ${ }^{(93)}$

- Professionnellement.

On relève 12 instituteurs, souvent intérimaires, 8 maîtres d'internat, 3 séminaristes, 1 professeur d'éducation physique, 4 policiers, 2 rédacteurs, 1 professeur du secondaire, 1 commis greffier, 1 attaché au parquet qui deviendra 
magistrat, 1 employé d'assurance. Chez les femmes, 3 enseignantes. En ce qui concerne les autres, elles évoquent leurs activités dans le scoutisme, elles ont souvent poursuivi leurs études.

Pour une vingtaine d'entre eux, on connaît l'origine sociale, 6 ont des parents commerçants ou artisans, 2 ont des parents de profession libérale, 4 ont des parents ouvriers ou employés, 3 ont des parents agriculteurs.

Il n'y a pas de grand changement avec ceux de 1942-1945 qui sont restés à l'Éducation surveillée.

\section{L'univers de l'éducateur en 1945-1950}

Ce n'est pas sans difficulté que nous avons essayé de reconstituer cet univers. Les entretiens que nous avons eus avec les éducateurs et les informations complémentaires que nous avons obtenues restituent des expériences vécues différemment et nous nous sommes trouvés confrontés, dans les entretiens comme dans les écrits, à de fréquentes contradictions qu'il n'est pas toujours facile d'éclairer. Au travers de ce matériau complexe, plus complexe que dans la génération précédente où la situation de guerre déterminait de nombreux points communs, nous nous sommes efforcés de regrouper des idées, des situations qui nous semblaient dominantes.

- Les conditions de vie, la volonté de "servir ", de " reconstruire "

"Servir, reconstruire " : voilà deux mots-clés que nous rencontrons souvent. Sur fond de la nécessaire reconstruction du pays, il y a aussi ce qui se réfere à la reconstruction de soi après des années difficiles.

Pour les jeunes éducateurs de l'après-guerre, les avantages de carrière sont très minces. Le plus souvent, ils sont titularisés comme éducateurs-adjoints et on ne devient éducateur qu'au choix, alors que les postes sont peu nombreux. Les traitements sont faibles, à peine supérieurs pour un éducateuradjoint à celui d'un moniteur pénitentiaire en début de carrière.

Paul Lutz écrit dans un rapport de 1945 que « le personnel est logé dans des conditions désastreuses dans les IPES. À Saint-Hilaire, les jeunes éducateurs logent au-dessus de l'étable et en sont réduits à se laver avec les gosses. Ceux qui ne sont pas de la région, lorsqu'ils sont mariés, sont le plus souvent séparés de leur famille et lorsque celle-ci peut loger dans l'établissement, on 
(94) Rapport de Paul

Lutz, 1945, Fonds Brisset, versement $n^{\circ} 20000111$, Centre des archives contemporaines, Fontainebleau.

(95) Fonds Brisset, versement $n^{\circ} 20000111$, centre des archives contemporaines, Fontainebleau.

(96) Ibid. leur demande très souvent une présence incompatible avec une vie familiale. Le système en trois temps, qu'est le fonctionnement de l'époque - l'éducateur est avec les jeunes de $7 \mathrm{~h}$ à $10 \mathrm{~h}$, de $12 \mathrm{~h}$ à $14 \mathrm{~h}$, et de $18 \mathrm{~h}$ à $21 \mathrm{~h}-$, devient souvent un service ininterrompu. " ${ }^{(94)}$

Comme les jeunes, les éducateurs sont souvent coupés de leur vie familiale, dans une sorte d'enfermement consacré au jeune et à l'institution.

Les institutions sont loin des villes lorsqu'elles ont un passé pénitentiaire, la relation reste difficile avec l'environnement immédiat, on sait que pour les habitants des villages environnants, les élèves des IPES continueront à être appelés « colons » pendant plus de vingt ans.

Un jeune éducateur stagiaire écrit en 1946 : «Du fait de l'isolement géographique de Saint-Hilaire, les communications avec l'extérieur sont quasi inexistantes, pas de foyer, pas de bibliothèque, l'éducateur doit se dépenser sans cesse, tenir l'attention des pupilles, les intéresser à leur redressement, les former, les sortir de leur abrutissement où ils tendent en permanence à se blottir. " (95)

Impressions sévères, désabusées à la fois sur la nature du travail avec les jeunes et sur la monotonie de la réalité quotidienne. C'est néanmoins ce même éducateur qui écrit : "J'ai la volonté et le désir de faire quelque chose, de fournir l'effort que tous les jeunes doivent apporter au relèvement du pays. Si je reste ici, je vais devenir routinier. " ${ }^{(9)}$ Beaucoup ne resteront pas.

Cette volonté de "servir " est aussi liée à l'idée de se réassurer. Certains éducateurs, nous l'avons vu, ont été prisonniers de guerre, d'autres viennent d'être démobilisés, il faut se réadapter à la vie civile, trouver un travail, il n'est pas toujours facile d'entamer ou reprendre des études. L'Éducation surveillée est une porte qui s'ouvre, un lieu relativement protégé qui se situe dans la continuité d'expériences collectives, découvertes dans les chantiers de jeunesse, les camps de prisonniers, dans l'armée. "Les professionnels que je rencontrais, dit un éducateur adjoint, recruté à Aniane, en 1946, n'avaient rien d'attrayants, on entrait dans un modèle disciplinaire très proche de celui de l'armée, comme je venais de terminer la guerre, je pouvais à la rigueur comprendre le rôle du chef de patrouille que certains éducateurs développaient. Je suis tombé sur la section "épreuve", j’avais été sous-officier pendant deux ans, j'avais l'habitude du commandement. »

Un éducateur du CO de Paris parle du « besoin de participer à une œuvre 
de reconstruction du pays. C'étaient les lendemains d'une drôle de victoire,

(97) Entretien de Jacques Bourquin avec Jacques Selosse, op. cit.

(98) Entretien de Jacques Bourquin avec Jacques Selosse, op. cit.

(99) Entretien de Jacques Bourquin avec René Moret, op. cit. 
(100) Entretien de Jacques Bourquin avec Jacques Selosse, op. cit.

(101) Sous la direction de Thierry Fillaut, Une IPES, Belle-Île-en-Mer, 1945-1977, Vaucresson, Service d'études, CNFEPJJ, 1996, p. 32.

(102) Guy Dutey, op. cit.
Comme les jeunes dont ils s'occupent, le jeune éducateur se sent sous surveillance : "Nous étions nous-mêmes sous surveillance, les éducateurs chefs assuraient en commun un rôle d'adjudant, il fallait leur remettre notre programme d'activités deux fois par jour, la situation de l'effectif... » ${ }^{(100)}$

Si à l'IPES de Saint-Maurice, avec la création dès la fin de la guerre de « la république ", René Courtois s'efforce de transformer l'ancien jeune détenu en citoyen, il n'en est pas de même à Belle-Île où la première tentative de réforme n'arrive que fin 1947, sans grande préparation préalable. Souvenonsnous qu'entre 1946 et 1947, l'IPES a reçu des jeunes qui ont participé pendant un temps à la milice ou à la division Charlemagne, le régime malgré la présence de quelques éducateurs reste celui du pénitencier. À Belle-Île, en 1948, chaque éducateur a la charge de 25-30 jeunes, il n'y a pas encore d'atelier de formation digne de ce nom, " les jeunes venaient de loin, ils étaient dépaysés, ils attendaient des nouvelles de leur famille, l'éducateur lisait et classait le courrier avant de leur distribuer, pendant ce temps on ne pouvait surveiller les gars, en plus ils n'avaient rien à foutre, ils n'étaient pas contrôlés, ils allaient faire des tours à Palais où ils rencontraient des filles qui travaillaient dans les conserveries ". ${ }^{(101)}$ Cette situation déboucha, courant 1948, sur des incidents assez graves avec la population et une mini-révolte dans l'institution à laquelle François Dhallenne, venu de Paris, mit fin.

Si le cas de Belle-Île est un peu marginal, son insularité en fera toujours une institution à part, le climat qui règne dans les nouvelles institutions n'est pas toujours à la hauteur des projets. Certains sont perceptibles, en particulier à Saint-Maurice, Saint-Hilaire et dans une moindre mesure à Saint-Jodard, ils privilégient l'acquisition d'un métier et de bonnes habitudes de vie à partir d'une pédagogie centrée sur l'atelier et le groupe où instructeurs techniques et éducateurs apparaissent comme complémentaires. On est dans une logique de reconditionnement, de réadaptation sociale. L'éducateur l'exprime ainsi : «Il faut faire progresser les jeunes en classe, à l'atelier, dans le groupe, leur apprendre à bien se tenir, à être correct, à avoir une bonne hygiène. L'apprentissage du métier c'était important, le CAP pour le jeune voulait dire la liberté. C'était en effet l'obtention du CAP qui conditionnait la fin du placement. " ${ }^{(102)}$

Dans les articles de l'époque, le travail est souvent associé à la liberté, dans les ateliers des slogans écrits en larges lettres, comme celui de l'atelier fer à Saint- 
Jodard : "Avec le travail, forge ton avenir".

René Courtois évoque à Saint-Maurice l'un des fondements de l'apprentissage, " les valeurs de la classe ouvrière à laquelle appartiennent les jeunes, la valeur du travail, la richesse du métier, l'apprentissage, école d'énergie et de courage ». ${ }^{(103)}$ "Mais tout cela, exprime un éducateur, peut être plus ou moins perverti par le climat de l'institution. À Saint-Maurice, le groupe "épreuve" subsiste, les jeunes y couchent en cages à poules, gare à celui qui ne trouve pas sa place dans une démarche d'apprentissage. " ${ }^{(104)}$

Paradoxalement, c'est chez ces éducateurs qui ont leur place à faire dans cet univers, que surgit cette idée, déjà rencontrée chez les moniteurs-éducateurs de 1937, et de 1943, que tout est à inventer. Sentiment qui se répercute d'une génération à l'autre comme si les choses restaient figées et que les prédécesseurs n'avaient rien fait.

Peut-être touchons-nous là une des caractéristiques de ce travail d'éducateur, le plus souvent empirique, au contenu plus ou moins insaisissable, échappant parfois aux institutions et aux savoirs, impression de tout réinventer à chaque instant, inventer contre les séquelles de l'esprit pénitentiaire avec l'inquiétude toujours sous-jacente qu'elles réapparaissent.

"Inventer quelque chose pour les jeunes que l'on apprend à découvrir, ils étaient difficiles mais ils étaient courageux, ils avaient une parole... On décorait, on peignait, on bricolait avec eux, on montait des scénettes, on se déguisait, on chantait, Au travers des cris et des jubilations, il s'instaurait une proximité relationnelle, il y avait des moments forts, j'ai toujours gardé un souvenir étonnant du silence au moment de la veillée quand je racontais des histoires, un ange passait, la rêverie ! " ${ }^{(105)}$

Ils avaient souvent 18 ans et plus, leur délinquance n’intéressait guère l'éducateur, il savait peu de choses sur leur passé, les enquêtes sociales étaient l'affaire du juge des enfants et du centre d'observation, le rapport d'observation n'encombrait pas les préoccupations de l'éducateur de l'IPES.

Dans les témoignages des éducateurs, ce qui apparaît surtout dans leur rapport au jeune c'est le souci de rencontre, de partage, leur donner les moyens pour s'en sortir.

Si l'instructeur technique dans son atelier et l'instituteur dans sa classe sont les armatures solides de l'internat dans un rôle bien défini et bien perceptible 
(106) « Le camp de montagne de Samoëns ", Rééducation, $\mathrm{n}^{\circ} 1,1947$. par le jeune, l'éducateur, lointain héritier du moniteur de la Pénitentiaire et du plus proche moniteur-éducateur, est en train de construire sa place à partir de sa vie quotidienne avec un groupe de jeunes qui se trouvent sous son autorité.

Dans cet univers éducatif fait de contradictions, où certains responsables veillent plus à éviter les incidents qu'à promouvoir de nouvelles activités, où la notion de risque éducatif n'est pas partagée par tous, le jeune éducateur peut être assez désemparé et craindre, comme il le dit, de se laisser aller « à la routine ".

\section{La professionnalisation en cours}

Les pratiques éducatives et institutionnelles commencent à évoluer, les relations des IPES avec l'environnement immédiat se modifient.

À Saint-Maurice, le journal Espère, publié par les jeunes dans le cadre de " la république », est largement diffusé aux populations environnantes, un moyen pour la direction d'expliquer les objectifs de la réforme.

À Saint-Hilaire, la vieille clique, derrière laquelle, depuis le milieu du XIXème siècle, les colons défilaient le dimanche au pas cadencé, va devenir, vers 1948, un orchestre de jazz et les jeunes participeront à l'animation des fêtes de village. Cette modification des liens avec l'environnement apparaît comme une priorité indispensable au projet de rééducation. Il faut, dans l'opinion, que l'image des " élèves " de l'IPES se substitue à celle des « colons ", cela ne se fera pas en un jour, la longue histoire des colonies pénitentiaires reste tenace.

En 1947, un éducateur de Saint-Hilaire, qui vient de partir en camp avec quelques jeunes, à Samoëns, en Savoie, écrit : "En tant qu'éducateur, je suis fier de la maison, je souhaite de tout cour que l'année prochaine, il y ait encore un camp pour les plus méritants de l'établissement. " (106)

On trouve des pratiques du même genre à Saint-Jodard et à Brécourt, chez les filles, le plus souvent liées au scoutisme.

Pour l'éducateur de 1948, l'impression d'un engagement provisoire s'estompe, il apparaît un sentiment d'appartenance à l'institution. Le bricolage de tous les jours, même s'il demeure, s'élabore quelque peu. Entre 1946 et 1950, Paul Lutz et Henri Michard, qui font de nombreuses inspections, donnent à 
celles-ci une véritable fonction de formation qui s'appuie sur la volonté de réforme des premiers directeurs (François Dhalenne, Dominique Riehl, René Courtois, Raymond Pailhès, Victor Ventré).

L'éducateur sait qu’il va rester. " On ne savait pas sur quoi ça allait déboucher, mais j’apprenais à aimer ce travail, sans savoir encore que c'était une profession. " ${ }^{(107)}$

L'éducateur s'installe, on le loge plus décemment, la proximité avec les gosses subsiste mais elle devient différente, le monde des jeunes et des éducateurs se distancie peu à peu, les complicités qui les avaient liées s'atténuent, l'éducateur se situe dans un projet institutionnel dont pour la première fois, il est un peu l'artisan. On entre dans une période d'élaboration et de structuration. Certains éducateurs, recrutés à cette époque, et qui travaillaient dans les IPES des années 1950, évoqueront, non sans nostalgie, "l'âge d'or de l'Éducation surveillée ». L'internat de rééducation apparaissait comme la formule idéale et les IPES évoluaient favorablement.

La démarcation qui s'opère progressivement entre l'éducateur qui se professionnalise et le jeune que l'on va inscrire dans une théorie de la délinquance va s'accentuer. Les sessions de formation de 1947-1950 vont y contribuer. Un des participants à ces sessions garde le souvenir d'une "pluralité de lectures stimulantes pour certains d'entre nous, mais il n'y avait pas de synthèse et le danger de plaquer sur des faits, des incidents, des canevas qu'on ne maîtrisait pas ". ${ }^{(108)}$ Étions-nous à l'heure des synthèses ?

Ces premiers regroupements autour de la formation permettent la prise de conscience d'une identité professionnelle. Ceci sera renforcé, à partir de 1947, par l'apparition d'une vie syndicale. Après la disparition, en 1946, d'un syndicat pénitentiaire, naît le Syndicat national de l'Éducation surveillée, rattaché à la Fédération de l'Éducation nationale (FEN.) C'est par son canal que les éducateurs commenceront à revendiquer des améliorations de conditions de travail, ce qui n'était pas superflu, mais surtout la nécessité qu'il y avait à créer un centre de formation. Tous les éléments de la professionnalisation sont réunis.

\section{2-1962 : La génération des "vaucressoniens"}

Le terme de "vaucressonien", qui se distingue de l'appellation des habitants de Vaucresson, les Vaucressonais, fut largement employé pour évoquer
(107) Entretien de Jacques Bourquin avec René Moret, op. cit.

(108) Entretien de Jacques Bourquin avec Jacques Selosse, op. cit. 
(109) Henri Michard, Sauvegarde, $\mathrm{n}^{\circ} 2,1951$. les premières promotions d'élèves-éducateurs. On peut faire l'hypothèse qu'Henri Michard, qui souhaitait affirmer l'identité du nouveau centre et de ses élèves, trouvait là une référence aux normaliens, les élèves des écoles normales d'instituteurs.

Le projet d'Henri Michard, élaboré dès les lendemains de la guerre, met l'accent sur le fait que « la formation de l'éducateur ne se limite pas au domaine de la connaissance théorique et pratique. Elle englobe une formation sur le caractère ». On parlerait aujourd'hui de la formation de la personne. « Toute formation doit être individualisée et permanente, elle se poursuit pendant toute la carrière, et doit s'articuler sur les recherches en cours. » ${ }^{(109)}$

\section{Le centre de formation et d'études}

Il est implanté, en 1951, à Vaucresson, dans un château proche de Paris, acheté par le ministère de la Justice. Henri Michard est nommé directeur de ce centre dont il souhaitait qu'il permette, géographiquement, des rapports et des liens étroits avec la direction de l'Éducation surveillée. Une propriété, suffisamment grande pour que les élèves-éducateurs puissent y être internes et y pratiquer des activités sportives.

Dès 1952, sont organisées quatre sessions de formation permanente qui accueilleront tour à tour les délégués à la liberté surveillée, les juges des enfants, les psychologues, les directeurs d'établissement. La première promotion d'élèves-éducateurs recrutée par concours national en 1952 sera formée à Vaucresson entre janvier et juin 1953. Aux 19 élèves-éducateurs/éducatrices recrutés, s'ajoutent 9 délégués permanents à la liberté surveillée, nouvellement nommés, qui ne relèvent pas encore de l'Éducation surveillée, ils sont recrutés sur titres, assistant social ou licencié en droit, par les tribunaux pour enfants. Ils ne relèveront du statut des personnels éducateurs de l'Éducation surveillée qu'en 1956.

Pour des raisons d'ordre pratique, cette promotion ne recevra qu'une formation théorique de 6 mois, suivie par un stage pratique de 3 mois et demi. Henri Michard regrette que le temps trop court empêche, parmi les enseignements proposés, la psychologie sociale et la sociologie différentielle.

L'année suivante, le temps de formation théorique sera porté à 7 mois et demi, chaque élève-éducateur étant tenu de rédiger une monographie sous la 
direction d'un des enseignants du centre. Parmi les monographies de cette promotion, 1954-1955, se dégagent trois types d'orientation :

- le groupe de jeunes en IPES ;

- les loisirs avec les jeunes, le milieu ouvert ;

- les " jeunes immigrés".

Dès 1955, la formation initiale ne s'oriente pas uniquement sur les pratiques d'internat, on évoque déjà le problème des jeunes immigrés, bien avant le regroupement familial des années 1970.

Pendant ce temps, les sessions de formation permanente se poursuivent, elles sont plus centrées sur l'internat :

- les activités de loisirs en 1954-1955;

- la pédagogie de groupe en internat en 1955 ;

- la conduite des groupes restreints en 1956.

Petit à petit, l'éducateur qui avait construit son identité en internat grâce au sport et aux loisirs, se sensibilise à la psychologie sociale appliquée, à l'animation des groupes. Il investit de nouveaux champs de compétence dans sa rencontre avec les jeunes, dont il partage la vie en internat.

Le projet de formation initiale s'enrichit progressivement, à partir de 1955. Les deux années de formation sont mises en place. Dès 1957, aux stages d'observation et d'IPES s'ajoute un stage en milieu ouvert auquel Henri Michard vient de consacrer une importante étude, suite aux expériences menées avec le centre d'observation public de Lyon et le centre d'observation privé de Dijon.

Les travaux monographiques des élèves-éducateurs sont de plus en plus orientés vers des enquêtes de terrain à dominante sociologique. Il y a, semblet-il, une volonté manifeste de la direction de l'Éducation surveillée de sortir l'éducateur du champ clos de l'internat, en lui permettant de mieux appréhender l'univers social des jeunes, tout en lui donnant de nouveaux outils d'intervention. Pierre Ceccaldi, directeur de l'ES, évoquera en 1962 « la transformation du rôle de l'éducateur du jeune délinquant, avec une ouverture toujours plus grande de son action sur la vie sociale. " ${ }^{(10)}$

À partir de 1956, est adjoint à la formation un stage en usine de trois semaines. Il s'agit de " mettre l'élève en situation de comprendre le monde du travail, la vie du monde ouvrier, le poids de la fatigue physique et nerveuse ».

On part du principe que les élèves-éducateurs ne sont pas issus de la classe

(110) Pierre Ceccaldi, in Henri Michard [sous la direction de], L'éducateur de jeunes délinquants, Vaucresson, CEFRES, 1962. 
ouvrière, ce qui n'est, en effet, pas le cas pour tous.

Le projet de Vaucresson sera l'objet d'un document de 220 pages, publié en 1962, au centre de formation et de recherche de l'Éducation surveillée, sous la direction d'Henri Michard : L'éducateur de jeunes délinquants.

\section{Le projet de formation initiale}

Le document que nous venons d'évoquer est à la fois un descriptif et un premier bilan des dix premières années de formation initiale.

On peut être questionné par le titre : Léducateur de jeunes délinquants. Depuis l'ordonnance du 23 décembre 1958 sur l'assistance éducative, le juge des enfants et l'Éducation surveillée ne limitent plus leur intervention aux mineurs délinquants, l'ES s'inscrit dans les politiques de prévention en intervenant, à la demande du juge, auprès des mineurs en danger. C'était un souhait déjà formulé dans le plan Costa de 1946 et dont les juges des enfants étaient porteurs, dès l'après-guerre. L'éducateur de l'Éducation surveillée ne peut plus être défini, uniquement par rapport à la délinquance juvénile. Il y a là une proximité de termes qui pèsera lourd auprès de l'opinion publique, qui associera souvent l'enfant en danger, qui relève du droit civil, à l'enfant délinquant, qui relève du pénal. L'enfant en danger était-il un délinquant en puissance?

Le document est préfacé par Jean Stœzel, professeur de psychologie sociale à la Sorbonne et directeur du centre d'études sociologiques, un proche d'Henri Michard. Ce choix est loin d'être anodin, car il signifie l'entrée, dans la formation des éducateurs, de la sociologie, de la psychologie sociale et le recul du pouvoir médical et plus particulièrement de la neuropsychiatrie infantile qui a été à l'origine de la plupart des écoles d'éducateurs.

Jean Stœzel définit l'éducateur de jeunes délinquants comme « celui qui doit rendre ses élèves sociaux, c'est-à-dire utiles à la société quand ils sont livrés à eux-mêmes et en même temps les amener à trouver satisfaisante la position qu'ils auront dans la société ».

La rééducation se fonde sur une logique de réinsertion et de réadaptation sociale. "Si à l'origine, écrit Pierre Ceccaldi, l'éducateur était enfermé dans les frontières étroites de l'internat, il doit exercer également ses fonctions en milieu libre, il travaille dans la cité, au cour des institutions sociales, il doit y prendre une place marquante. " (111) 
De nouveaux horizons s'ouvrent pour l'éducateur, ils se concrétiseront avec l'inscription de l'Éducation surveillée au IVème Plan, en 1962.

- Le concours national

C'est le concours qui permet d'être retenu en tant qu'élève-éducateur, après une sélection préalable qui comporte des examens médicaux, psychologiques et psychiatriques, à base d'entretiens et de tests projectifs. "L'objectif est de détecter les inaptitudes. "

Le concours proprement dit comporte une épreuve de mise en situation, pendant 15 jours, dans une IPES où le candidat est mis en contact progressif avec les jeunes et les réalités de la vie quotidienne, il doit mener certaines activités (veillées, sport, classe). Cette épreuve est d'autant plus sélective que certains candidats décident d'eux-mêmes de ne pas poursuivre.

Ils sont ensuite soumis à une épreuve écrite et orale en lien avec les activités de la mise en situation et les objectifs de l'établissement.

- La formation théorique

Henri Michard insiste sur l'aspect à la fois ambitieux et nuancé de cette formation. "Il ne s'agit pas de rendre l'élève-éducateur capable de résoudre tous les problèmes qui se posent à lui, la formation théorique doit révéler leur existence, leur nature, le mettre en garde et lui permettre d'éviter les plus grosses erreurs. Il s'agit de faire acquérir des connaissances, une capacité de jugement et par-là atteindre la personnalité tout entière. " ${ }^{(12)}$

Sans négliger la biologie et la neuro-psychiatrie, le contenu de la formation laisse une place importante aux sciences sociales et aux méthodes pédagogiques.

(112) Henri Michard, Sauvegarde, op. cit. Il comporte trois grands domaines :

- connaissance de l'enfance inadaptée

* facteurs somatiques de la personnalité, 20h ;

* psychologie générale, $100 \mathrm{~h}$;

* psychologie de l'enfant et de l'adolescent, 40h ;

* psychologie sociale, $30 \mathrm{~h}$;

* sociologie, $45 \mathrm{~h}$;

* neuropsychiatrie, $20 \mathrm{~h}$;

* facteurs de la délinquance juvénile, 30h 
(113) Entretien de Jacques Bourquin et Vincent Peyre avec Henri Michard, op. cit.
- les méthodes

* pédagogie générale, $12 \mathrm{~h}$;

* psychopédagogie, $30 \mathrm{~h}$;

* pédagogie spécialisée (observation, rééducation, milieu ouvert), 100h ;

* méthodes d'éducation populaire, $60 \mathrm{~h}$

- éducation physique et sportive, $200 \mathrm{~h}$

- droit et institutions

* droit, $35 \mathrm{~h}$;

* institutions, $50 \mathrm{~h}$;

* gestion, $15 \mathrm{~h}$.

À partir de 1956, apparaîtront des séquences de dynamique de groupe.

Henri Michard, que nous avons rencontré avec Vincent Peyre en 1995, nous explique comment il fut amené à constituer l'équipe des enseignants, à partir de 1952 :

" J'ai introduit la sociologie dans la formation avec Jean Dumazedier, spécialiste de la sociologie des loisirs. Je le rencontrais à Peuple et Culture.

" Je connaissais Didier Anzieu, psychanalyste, c'est lui qui m’a fait rencontrer Jean Maisonneuve qui revenait des États-Unis et introduisait en France les techniques sociométriques et les premières pratiques de dynamique de groupe, un des pionniers de la psychologie sociale. C'est mon ami Georges Heuyer qui m'a fait connaître Jean-Louis Lang, un de ses élèves, qui assurera les cours de neuropsychiatrie infantile.

" J'ai peut-être apporté trop d'importance à la sociologie : de jeunes chercheurs du CNRS, Lahalle, pour la sociologie du travail et de la classe ouvrière, Jenny pour la sociologie de la famille, Marie-Jo Chombart de Lawe en sociologie urbaine... Vaucresson était porteur d'un projet, celui du milieu ouvert pour lequel on travaillait depuis 1952, le passage de la rééducation en internat à une rééducation plus complexe, plus individualisée, nécessitait des ouvertures. C'était assez mal vu sur le terrain. La psychanalyse est arrivée un peu plus tard, au milieu des années 1960, dans le cadre de la formation permanente. " ${ }^{(113)}$

Henri Michard insiste sur le rôle important à donner à l'éducation populaire dans le cadre de la formation, c'est là que les éducateurs vont chercher une bonne part des outils pédagogiques dont ils ont besoin (théâtre, club de lecture, télé-club, chorale.) Henri Michard sollicite les militants de Peuple et 
Culture dont il est très proche. "Joffre Dumazedier, Benigno Cacérès, Gilles Ferry étaient porteurs de projets qui me semblaient très adaptés aux problèmes avec les jeunes dans les institutions. »

Le sport était largement développé avec Georges Durand, professeur d'éducation physique.

En fin de formation théorique, la promotion passait 5 semaines pour s'initier aux techniques éducatives à l'Institut national d'éducation populaire de Marly-le Roi.

Parmi les autres intervenants, des membres de l'équipe fondatrice de l'Éducation surveillée : Guy Sinoir, chargé de l'enseignement de la psychologie et dont les interventions ont profondément marqué les générations de "vaucressoniens". Il s'agissait autant de leur apporter un savoir que " de leur permettre d'acquérir un mode de penser ». ${ }^{(114)}$ Paul Lutz, magistrat, était porteur, avec un grand talent, des récits fondateurs de l'Éducation surveillée, une préfiguration de l'histoire.

On est étonné de l'absence, dans cet enseignement, des directeurs d'institutions de l'Éducation surveillée, à l'exception de René Courtois, directeur de l'IPES de Saint-Maurice, dont l'établissement demeure une référence. On ne rencontre ni Dominique Riehl, directrice de Brécourt depuis 1947, ni François Dhallenne, directeur du CO de Savigny depuis 1945, pourtant tous deux sont des figures pionnières et ils ont eu un rôle important dans les sessions de formation de 1947 à 1949. Il est à remarquer que dans le projet de Vaucresson, la rééducation des filles n'est jamais abordée, cela reste un secteur mineur pour l'Éducation surveillée. Quant à Henri Michard, il avait plus de lien avec le CO de Lyon, lieu d'expérimentation de l'observation en milieu ouvert, qu'avec l'équipe du CO de Savigny.

Tout cela laisse augurer que l'apport théorie-pratique ne sera pas simple.

- La formation pratique

Le chapitre qui lui est consacré commence par une formule un peu sibylline : "La formation pratique ne doit pas être sous-estimée ni surestimée ", ${ }^{(115)}$ une sorte de mise en garde à l'égard de la formation pratique qui fut longtemps la seule référence formative, " la formation sur le tas ", disaient les premiers éducateurs.
(114) Henri Michard [sous la direction de], L'éducateur..., op. cit., p. $46-47$.

(115) Henri Michard, Sauvegarde, op. cit. 
(116) Ibid.

(117) Jean-François Chosson, Pour l'Histoire, Bulletin de l'AHES-PJM, $\mathrm{n}^{\circ} 24$, septembre 2000 .
L'objectif du stage pratique est clair : l'apprentissage des quatre fonctions principales de l'Éducation surveillée : l'internat, la liberté surveillée, l'observation en centre et en milieu ouvert.

Henri Michard exprime toutefois quelques craintes quant « au caractère un peu trop systématique de cette formation. Il ne faut pas, ajoute-t-il, s'orienter vers la formation d'éducateurs standard, scientifiques et conditionnés ». ${ }^{(11)}$ Afin d'atténuer une modélisation trop forte de l'éducateur par la pratique du terrain, le projet de Vaucresson s'efforce de structurer le contenu et le déroulement du stage pratique par des travaux et des comptes rendus que le stagiaire doit rendre régulièrement au centre de formation. On est dans une logique de dualité terrain-école, dans laquelle il faut accorder autant d'importance aux pratiques existantes qu'aux pratiques novatrices à construire.

Jean-François Chosson, élève-éducateur de la première promotion, écrit dans un article : "Au cours de ce périple de formation entre Vaucresson et le terrain, j'ai entendu cinq discours différents sur le métier d'éducateur, apparemment cohérents et argumentés en fonction des objectifs, des missions et des méthodes souvent contradictoires ; le formalisme administratif du directeur de Neufchâteau, le discours psychologisant au moment de la sélection à Vaucresson, le discours militariste et pédagogique lors de mon stage à Neufchâteau, le discours philosophique, celui de Vaucresson, humaniste et imprégné de scoutisme avec Paul Lutz, personnaliste avec Henri Michard, pédagogique et militant avec Joffre Dumazedier, Benigno Cacérès et Peuple et Culture. C'est cette dernière approche qui m'a apporté la cohérence et la méthodologie dont j'avais besoin. " ${ }^{(117)}$

- L'examen d'aptitude professionnelle

Il clôture les deux années de formation et comporte une épreuve écrite, à base de questions dont une au moins doit être traitée sous forme de dissertation. À cela s'ajoutent des épreuves orales sur l'ensemble des matières et la soutenance de la monographie. Les notes de l'ensemble des stages pratiques comptent pour la moitié des points.

Les résultats font l'objet d'un classement de sortie et l'éducateur stagiaire devient, en cas de réussite, éducateur titulaire. Il n'y a pas de diplôme de fin de sortie, la titularisation en tient lieu. 


\section{L'atmosphère de Vaucresson}

Enseignants et élèves ont beaucoup parlé de l'atmosphère "feutrée " de Vaucresson, à cette époque.

Les promotions nationales, qui oscillent entre 15 et 20 stagiaires, constituent des petits groupes à l'intérieur desquels les relations élèves-éducateurs, enseignants sont privilégiées et où le cours magistral est à la fois transmission de savoirs, d'échanges et de débats. Pierre Ceccaldi l'exprime dans sa post-face : "C'était une formule de luxe qui a eu le grand intérêt de permettre des expériences qui n'auraient pas été possible avec un plus grand nombre d'élèves. "(118)

Un autre aspect de la vie communautaire à Vaucresson est lié à l'internat obligatoire, élément important du projet. C'est un univers très paternaliste, la promotion vivant une proximité quotidienne avec le directeur et sa famille. Tout le monde habite le château : Henri Michard et sa famille logent au ler étage avec les quelques filles de chaque promotion, tandis que les garçons habitent le 2ème étage.

Cette vie collective, Henri Michard y accorde une grande importance. Il écrit à ce sujet : «Elle a entraîné des conséquences qui débordent largement le secteur de la formation. Il y avait, à Vaucresson, moins de distance entre le directeur de l'Éducation surveillée, Pierre Ceccaldi, qui y venait régulièrement faire du sport avec la promotion et un simple élève-éducateur, que dans un établissement entre le directeur et un éducateur chevronné. Cette situation a été un des facteurs qui ont aidé à se libérer des vieux cadres et à évoluer vers un système de relations moins pesant, plus souple. " ${ }^{(119)}$

N'oublions pas que la majorité des internats de l'Éducation surveillée avait un passé pénitentiaire encore tout proche avec des pratiques très hiérarchisées.

Henri Michard conclut en disant : "Cette évolution était nécessaire pour que puissent être mises en place des méthodes pleinement éducatives. " ${ }^{(120)}$

Créer, favoriser des réseaux de relations entre les élèves, les enseignants, les chercheurs, qui apparaissent en 1958, les membres de la direction de l'Éducation surveillée, c'était construire un noyau dont on pouvait espérer qu'il serait porteur de nouvelles doctrines, de nouvelles orientations, de pratiques à venir et contribuer à la structuration d'une identité professionnelle.

Sortir de Vaucresson, c'était pour les stagiaires un label de qualité qui fondait une identité professionnelle valorisante en donnant cette possibilité, à

\author{
(118) Pierre Ceccaldi, \\ in Henri Michard \\ [sous la direction de], \\ L'éducateur..., op. cit., \\ p. 232.
}

(119) Henri Michard, «Dix années de formation d'éducateurs à

Vaucresson ", Rééducation, $n^{\circ} 160,1963$, p. 18.

(120) Ibid. 
(121) Fonds Brisset, versement $\mathrm{n}^{\circ} 20000111$, Centre des archives contemporaines, Fontainebleau. moyen terme, d'appréhender le devenir, l'évolution de l'Éducation surveillée. Le 23 avril 1956, était promulgué un nouveau statut de l'éducateur de l'Éducation surveillée, il succédait à celui du 10 avril 1945. Inspiré de celui des instituteurs, il officialisait la formation, il apportait une amélioration sensible de la rémunération des éducateurs dont l'indice terminal, dans ce grade, passait de 360 à 430. On supprimait le grade intermédiaire d'éducateur adjoint. Ce statut opérait la fusion entre les éducateurs de l'Éducation surveillée et les délégués permanents à la liberté surveillée. Il s’agissait, est-il mentionné dans le rapport annuel 1956 de l'Éducation surveillée, « de rapprocher les méthodes de rééducation en internat et en cure libre. La compétence de l'éducateur doit s'accroître, il pourra aussi bien intervenir dans les IPES que dans un centre d'observation, dans un service de milieu ouvert, en foyer, dans un service de liberté surveillée, au centre de formation et d'études de Vaucresson ». (Le premier éducateur, chargé de formation, à Vaucresson, Jean-François Chosson, y sera nommé en 1959.) Comme on le dira 10 ans plus tard, l'éducateur est en train de s'approprier sa propre formation.

\section{Regard porté sur les "vaucressonniens"}

On compte 210 élèves-éducateurs et éducatrices formés à Vaucresson entre 1952 et 1962, soit 165 hommes et 45 femmes. Ajoutons uniquement, pour mémoire, que les promotions 1952 et 1953 reçurent 17 délégués permanents à la liberté surveillée, dont on préparait prochainement le rattachement à l'Éducation surveillée. C'était pour la majorité des assistantes sociales professionnalisées depuis plusieurs années. Elles ne font pas partie de notre échantillonnage.

C'est à partir des fiches de renseignements administratifs, que les candidats au concours envoyaient à Vaucresson, ${ }^{(121)}$ que nous avons établi une sorte de profil de ces élèves-éducateurs et éducatrices. Il concerne 112 élèves, soit la totalité des promotions de 1955 à 1961 . 
Leur âge à l'arrivée à Vaucresson

\begin{tabular}{l|c|c}
\hline & Hommes & Femmes \\
\hline $18-21$ ans & 12 & 13 \\
$21-24$ ans & 29 & 15 \\
$25-29$ ans & 23 & 8 \\
30 ans et + & 9 & 3 \\
\hline \multirow{2}{*}{ Total } & 73 & 39
\end{tabular}

Concernant l'âge, il est à remarquer qu'à partir de 1955, l'Éducation surveillée pourra recruter des éducateurs sous contrat pour lesquels les diplômes requis pour passer le concours ne sont pas nécessaires. Après trois ans d'activité en tant qu'éducateur contractuel dans les établissements d'éducation surveillée, le concours leur est ouvert. Ils sont donc en général plus âgés que les candidats du concours externe ; leur moyenne d'âge se situe entre 25 et 30 ans. Le premier éducateur contractuel intègre la promotion 1959, ils seront 9 dans la promotion 1960 , soit $1 / 3$ de cette promotion, et 15 dans celle de 1961, soit la moitié. Ce sont en règle général des hommes, l’Éducation surveillée ne disposant à la fin des années 1950 que de deux établissements de filles. On ne parle pas encore de mixité dans les équipes éducatives.

L'arrivée des éducateurs contractuels est liée pour l'Éducation surveillée à plusieurs objectifs dont en particulier celui de l'âge de recrutement des éducateurs. Elle trouve un peu trop jeunes les éducateurs recrutés au concours externe. À cela s'ajoute le souhait de ne pas limiter le recrutement à de jeunes bacheliers mais de l'ouvrir à des candidats qui ont eu d'autres cursus, des expériences professionnelles, et vraisemblablement aussi le souhait d'intéresser des jeunes gens plus proches du milieu social des jeunes dont ils auront à s'occuper. Il y a dans ce souhait un souci de promotion sociale. Un autre argument, qui n'est pas des moindres, c'est de pouvoir bénéficier d'un recrutement parallèle, alors que les postes mis au concours sont manifestement insuffisants. Promotion 1954 : 18 élèves. Promotion 1955 : 14 élèves. Promotion 1956 : 17 
élèves. Promotion 1957 : 19 élèves. Promotion 1958 : 16 élèves. Promotion 1959 : 16 élèves... Enfin, ultime argument : les éducateurs contractuels reviennent moins chers que les titulaires pendant leur temps de contractualat.

- Diplômes et études poursuivis avant le concours

Nous distinguerons les candidats du concours externe et ceux du concours interne.

Concours externe : 87 élèves-éducateurs et éducatrices. 70 sont titulaires du baccalauréat, les autres d'un diplôme équivalent : brevet supérieur, capacité en droit, BEC, diplôme d'école nationale professionnelle, diplôme d'une école d'éducateur du secteur privé. Parmi les bacheliers, la moitié a entamé des études supérieures mais ne les a guère poursuivies au-delà de 2 ans (droit : 11 ; sciences : 9 ; lettres : 7 ; institut de psychologie : 2 ; médecine : 2). D’autres ont tenté la préparation à Saint-Cyr, Navale, CREPS, école normale d'instituteurs. 2 ont commencé le grand séminaire. 3 des candidats sont titulaires d'une licence en droit dont 2 femmes, une élève-éducatrice est titulaire du CAP d'institutrice.

Concours interne : 25 élèves-éducateurs et éducatrices. La majorité a suivi des études secondaires ou techniques. 14 sont titulaires du BEPC, 3 possèdent un CAP (tourneur, ajusteur...).

- Les antécédents professionnels

Concours externe. 1/3 des candidats ont eu des activités professionnelles antérieures, le plus souvent comme instituteur intérimaire ou maitre d'internat, quelques-uns ont été éducateurs dans le secteur privé. On trouve des employés administratifs (PTT, clerc d'avoué, secrétaire, aide comptable), emplois qui accompagnaient pour certains la poursuite des études.

Concours interne. La presque totalité des éducateurs contractuels ont eu des emplois antérieurs à leur contrat à l'Éducation surveillée. On trouve 5 militaires qui avaient souscrit à des contrats de 3 à 5 ans avec l'armée, parfois après leur service militaire en Algérie. Il y a 5 employés de bureau, 2 instructeurs à la formation professionnelle, 4 ouvriers, 2 éducateurs dans le secteur privé, 1 moniteur d'éducation physique et quelques emplois divers dans le commerce. 
- Activités de type socio-éducatif

51 élèves-éducateurs sur 73 répondent à cette question, en évoquant le plus souvent des responsabilités. La proportion est plus faible chez les élèveséducatrices : 20 sur 39.

Globalement, l'influence du scoutisme et des mouvements de jeunesse est dominante. Chez les garçons, 16 ont pratiqué le scoutisme au moins 4 ans, 8 d'entre eux y ont des responsabilités de chef de troupe ou de district. À cela s'ajoutent un responsable du mouvement Cour Vaillant (les patronages catholiques), 4 responsables de patronages laïcs, 9 moniteurs ou responsables de colonies de vacances. Chez les filles, 14 ont pratiqué le scoutisme, dont 12 en tant que cheftaines, auxquelles il faut ajouter une dirigeante Âmes Vaillantes, une instructrice des CEMEA et 4 monitrices de colonies de vacances.

Beaucoup d'élèves-éducateurs ou éducatrices évoquent des responsabilités dans des activités culturelles et sportives. Il y a manifestement chez la majorité d'entre eux une pratique ancienne des activités avec les jeunes, intérêt qui n'est pas sans lien avec l'idée de professionnaliser ces activités.

- Le milieu social d'origine

Les éléments dont nous disposons concernent uniquement le métier des parents et plus particulièrement du père.

Pour une douzaine d'entre eux, on peut parler de milieu aisé, voire bourgeois. Pères : ingénieurs, magistrats, cadres supérieurs, professions libérales. Ce sont plutôt les élèves-éducatrices qui sont issues de ce milieu.

Pour plus d'un tiers, on peut parler de classe intermédiaire : commerçants, artisans, enseignants, fonctionnaires.

Les autres proviennent de milieux plus modestes dont une trentaine dont les parents sont employés ou ouvriers.

La majorité de ces élèves-éducateurs et éducatrices est d'origine citadine.

- Les motivations

L'ultime question du document de Vaucresson envoyé aux élèves-éducateurs/ éducatrices porte sur " les motivations du choix de la profession ». Les réponses sont lacunaires, évasives. Il est vrai qu'il s'agit d'un document officiel en vue d'une sélection. Le candidat qu'il soit contractuel ou non ne sait pas très bien 
(122) Annales de Vaucresson, CEFRES, 1975 p. 33-37 ; $1976-$ 1977 p. $111-147 ; 1978$ p. 209-220. comment sera interprétée sa réponse, il y a une certaine prudence à avoir. Que relevons-nous ? La recherche d'un métier utile, positif. On ne parle plus de " servir », comme au lendemain de la guerre, on s'achemine vers une image qui sera le leitmotiv du recrutement des éducateurs à partir de 1963, au moment ou l'Éducation surveillée inscrite au IVème Plan pourra recruter des éducateurs en beaucoup plus grand nombre : "Un métier jeune parmi les jeunes. »

Cette question de motivation, nous y ferons référence à partir d'un travail entrepris au centre de Vaucresson par deux psychologues, Marie-Thérèse Mazerol et Joseph Villier, déjà rencontré en tant qu'éducateur à la fin de la guerre. Il s'agit d'une recherche exploratoire sur la sélection des éducateurs et plus particulièrement sur leurs motivations. Ils rencontrent, entre 7 et 15 ans après leur titularisation, 38 éducateurs et 24 éducatrices recrutés en 1951 et 1967, dont une majorité de "vaucressonniens".

Ce travail fut publié entre 1975 et 1978 dans les Annales de Vaucresson. ${ }^{(122)}$ La question de fond était : "Pourquoi devenir éducateur, ce métier n'est pas anodin, qu'est-ce qui y pousse ? " L'enquête fut menée à base d'entretiens et de tests projectifs auxquels avaient été soumis les candidats lors de leur sélection.

Marie-Thérèse Mazerol et Joseph Villier furent amenés à distinguer les raisons à caractère économique, situationnel, et ce qui pouvait apparaître comme des motivations beaucoup plus personnelles. Le métier d'éducateur n'était-il qu'une éventualité parmi d'autres professions : enseignants, médecins, infirmiers... ? Ils évoquent chez les éducateurs comme chez les éducatrices à des degrés divers :

- un choix professionnel par culpabilité d'une situation moins prestigieuse que celle qu'on aurait pu envisager ;

- un choix professionnel lié à des motivations qui visent inconsciemment à la réparation de déficits passés... : l'insécurité, l’insatisfaction affective, les problèmes de communication, de santé, qui plus particulièrement suivant le cas aspiraient à se réparer dans l'exercice de la profession d'éducateur ;

- un choix professionnel pour des raisons identificatoires : identification à un modèle ; identification à ce qui a pu être perçu ou imaginé des désirs d'une personne signifiante de l'environnement : le père... ; identification beaucoup plus lointaine à des enfants ressentis comme frustrés et déterminant secondairement un besoin de réparation inconscient. 
Les auteurs concluent : «De toute manière, les motivations ne sont jamais simples et le choix de la profession est toujours surdéterminé. »

- Un questionnaire adressé à une cinquantaine de "vaucressonniens", en 2005

Courant 2005, soit environ 50 ans après leur entrée à l'Éducation surveillée, nous avons envoyé un questionnaire par lequel nous souhaitions les interroger sur le souvenir de leur rencontre avec l'Éducation surveillée. Nous avons reçu 20 réponses et réalisé 3 entretiens. À l'exception de deux d'entre eux, qui en cours de carrière étaient entrés dans le secteur associatif de l'éducation spécialisé, tous les autres étaient restés à l'Éducation surveillée ; où la quasi-totalité d'entre eux avait fini leur carrière en tant que directeur, une y était devenue psychologue.

Les réponses que nous avons obtenues confirment bien tous les points évoqués dans les pages précédentes. Un passé de mouvements de jeunesse, l'abandon d'études supérieures, pour beaucoup le besoin de gagner sa vie : "Il fallait que je trouve un emploi après un long service militaire, j’étais marié, j'avais 2 enfants, l'Éducation surveillée m’est apparue comme une bénédiction." "

On trouve dans l'intérêt à s'occuper de jeunes, la référence pour les hommes à la guerre d'Algérie, à un service militaire qui a duré pour certains jusqu'à 30 mois, une expérience de longue vie collective avec les jeunes du contingent, assez souvent dans une position de commandement - plusieurs ont été officiers. Le retour dans la vie civile n'est pas toujours facile, l'éventualité de reprendre des études, si l'on n’a pas été sursitaire, n'est pas évidente. "En Algérie, dit l'un d'entre eux, on me confiait des jeunes punis de jours d'arrêt, plutôt que de les mettre en cellule [...] Au sommet de notre piton, je leur dois de m'avoir donné envie de continuer quelque chose dans le civil avec des jeunes pas tout à fait comme les autres. »

Dans ces motivations émergent des choses plus profondes. Un candidat avait envisagé la prêtrise puis avait choisi d'entrer comme éducateur à l'Éducation surveillée, « une voie qui me permettait d'abandonner ce projet de prêtrise sans trahir. " Un autre, jeune ouvrier, syndicaliste, jociste s'occupe bénévolement de jeunes délinquants avant de devenir éducateur contractuel à l'Éducation sur- 
veillée. Le choix des éducatrices apparaît, encore plus que chez les éducateurs, lié à un passé de mouvements de jeunesse, d'animations multiples avec des jeunes. L'une d'elles écrit : " J'avais envie de poursuivre dans un cadre professionnel ce que j’avais fait avec les jeunes dans le domaine des loisirs. "

Si l'année passée à Vaucresson est appréciée sans réserve - " nous avions le temps de formaliser, d'approfondir le sens de l'action, mettre de l'ordre dans le brouillard de nos convictions »-, la rencontre avec les institutions et la pratique éducative avec les jeunes laissent des souvenirs plus ambivalents, voire parfois franchement négatifs : "Ce qui choque, écrit un candidat qui découvre l'IPES de Saint-Hilaire, c'est qu'il faut se conformer aux règles d'un milieu dont le fonctionnement global et la raison d'être, nullement explicitée, échappent totalement au candidat éducateur... Le mitard, le caïdisme entretenu par l'institution ne correspondent en rien au projet éducatif. "

Un stagiaire de l'IPES de Saint-Maurice a du mal à faire des liens entre ce qu'il a appris à Vaucresson et les ouvertures apportées par la psychologie sociale et la réalité du terrain : "Ce sont des rapports de force continuels entre jeunes et adultes... La tension est quasi-permanente, on vit dans l'angoisse de la fugue... Par contre, la classe et les ateliers sont les fleurons de l'établissement. " Impression que l'éducateur n'a pas encore vraiment sa place dans le projet de rééducation, sa légitimité est encore à conquérir.

D'autres évoquent leur stage en centre d'observation. «À Savigny, écrit l'un d'eux, l'institution relève surtout de l'enfermement, de la discipline. Il y a 200 jeunes, la dimension collective du projet tue l'approche individuelle... » Il évoque toutefois « le sérieux, la qualité de l'observation, l'intérêt qu'il y porte ».

L'Éducation surveillée est en pleine recherche, le regard posé par deux stagiaires sur le centre d'observation de Lyon qui vient d'ouvrir en 1951 est totalement différent : "C'est un lieu novateur, ouvert à l'initiative individuelle, dénué de toute forme d'autoritarisme... un lieu précurseur qui accordait une grande importance à toutes les activités culturelles, sportives, très imprégnées des techniques d'éducation populaire. "Ce n'est pas étonnant qu'Henri Michard ait, dès 1952, choisi le CO de Lyon pour expérimenter les premières techniques d'observation en milieu ouvert.

Trois éducatrices de notre échantillonnage ont fait leur stage à l'IPES de filles de Brécourt. Le souvenir en est particulièrement négatif. Pourtant, en 
1947, au moment de sa création, l'institution était considérée comme une véritable innovation de l'Éducation surveillée dont la directrice évoquait " l'ambiance saine, gaie, éminemment favorable à l'abandon des attitudes et à l'épanouissement de la personne vraie ». Ces éducatrices, rappelons-le, avec près de 50 ans de recul, évoquent " une direction lointaine et autocrate ». ${ }^{(123)}$ Une autre parle de " l'atmosphère étouffée de Brécourt, totalement coupée du monde extérieur où les filles qui étaient là ne voyaient jamais leur famille considérée comme malsaine ». Une troisième parle du " climat malsain et néfaste de l'institution autant pour les filles que pour les éducatrices ». Aucune de ces trois éducatrices ne souhaita revenir à Brécourt au cours de leur carrière. Cette stigmatisation de Brécourt, qui dura longtemps parmi les jeunes éducatrices, on ne la retrouve pas avec autant de virulence dans les IPES de garçons. Il est vrai qu'il y en avait plusieurs, elles étaient différentes les unes des autres, des directeurs s'y succédèrent, ce qui n'était pas le cas de Brécourt où l'équipe fondatrice resta environ 20 ans. Pour les éducateurs, le passage en IPES était souvent un passage obligé pour accéder rapidement à la hiérarchie. Certains "vaucressonniens" les dirigèrent lorsqu'elles devinrent ISES (institutions spéciales d'éducation surveillée) à la fin des années 1970.

Quels que soient les internats de garçons et les évolutions, une idée assez forte subsistait : "C'est là, au contact des jeunes, qu'on apprenait son métier dans le quotidien."

\section{Pour conclure}

Ce qui nous semble avoir réellement marqué les éducateurs de l'Éducation surveillée des premières générations, au moins jusqu'au milieu des années 1960 - et cela les différencie de leurs collègues du secteur associatif -, c'est la situation de dualité, souvent d'antagonisme qu'ils ont vécue, tout d'abord avec les personnels pénitentiaires et ensuite avec les survivances de la culture pénitentiaire.

L'échec de la première réforme de Saint-Maurice, où l'on prétend substituer des instituteurs surnuméraires, avec leur référence au scoutisme, au personnel pénitentiaire, a vraisemblablement disqualifié les " éducateurs " des maisons d'éducation surveillée. Malgré cela, les campagnes de presse ont produit leur effet, on ne peut refuser la réforme, c'est sur ses bases que s'institue la dualité
(123) Béatrice Koppel,

« Le temps fort de la rééducation des filles ", Cahiers du CRIV, $\mathrm{n}^{\circ} 2$, Vaucresson, octobre 1986, p. 88 . 
des personnels pénitentiaires et éducatifs dans les maisons d'éducation surveillée. On demeure dans une logique réformiste, on n'est pas dans un processus de rupture, ceci pèsera lourd dans l'évolution du système éducatif et sur la difficulté que l'éducateur aura à se situer jusqu'à la fin des années 1950 .

En 1937, le moniteur-éducateur est un intrus, il l'est encore en 1942, alors que le discours des théoriciens en privilégie le rôle. Il est tiraillé entre deux options, l'une répressive et éducative que les directeurs de l'époque s'efforcent de concilier, en espérant modifier l'une au contact de l'autre : une option répressive, disciplinaire qui n'en finit plus de mourir, parce que vraisemblablement perçue comme nécessaire et une option éducative dont on a encore mal repéré les perspectives, les contours.

En réponse à ce dilemme, le jeune éducateur se vit dans la complicité des " gosses " plus ou moins contre l'institution (il serait intéressant de savoir si les gosses vivaient la même chose !)

Jusqu'où peuvent aller ces complicités sans devenir une marginalité intolérable pour l'institution et une position peu crédible pour le jeune ?

Le départ massif des moniteurs-éducateurs après la libération n’a-il pas été une autre réponse?

Historiquement, tout se règle en 1945 : autonomie conquise sur l'Administration pénitentiaire, nouveau statut des personnels... Ces textes tirent l'Éducation surveillée de l'ombre pénitentiaire pour la transporter à la pleine lumière des idéaux des lendemains de la guerre. Pourtant, sur le terrain, ce n'est pas ce qui se joue, s'il y a rupture institutionnelle avec l'Administration pénitentiaire, la dualité subsiste dans toutes ses formes les plus insidieuses. De nombreux personnels pénitentiaires nouvellement intégrés au cadre éducatif continuent, malgré leurs bonnes intentions, à perpétuer les traditions dont ils sont porteurs. Les institutions ne changent guère, ce sont les mêmes lieux, le même environnement (en 1965, dans le voisinage des IPES, les habitants continuent à parler des colons), les mêmes locaux. On mettra deux ans à Saint-Hilaire pour supprimer les cages à poules mais bien plus longtemps à Aniane, à Saint-Maurice, à Saint-Jodard. S'il n'y a plus de dualité des personnels au niveau statutaire, celle-ci subsiste au niveau des mentalités.

Malgré cela, il y a une mutation progressive qui s'opère. L'éducateur finit par se légitimer dans le vécu avec les jeunes, tout cela en dehors des discours 
théoriques sur l'enfance délinquante. C'est par cette auto légitimation que l'éducateur prend petit à petit conscience de sa place dans l'institution à côté de l'instituteur et de l'enseignant professionnel. Le chemin sera long et difficile, mais l'avenir est pour lui, il va rester. C'est une autre époque qui s'ouvre à partir de 1947. Il a un premier statut en 1945, il en aura un second en 1956, il réclame une formation, elle se mettra vraiment en place à Vaucresson à partir de 1952.

Tous les éléments de la professionnalisation sont réunis. Les projets des institutions vont lentement évoluer, l'éducateur y aura sa part. Les "vaucressonniens" choqués par les lourdeurs pénitentiaires qui subsistent vont, dans la continuité de leur prédécesseur, s'engager dans des pédagogies plus ouvertes centrées dans un premier temps sur le groupe de jeunes, avec la volonté - c'est un des résultats de la formation reçue à Vaucresson - d'individualiser progressivement cette réponse.

La poussée de croissance de l'Éducation surveillée avec son inscription au IVème Plan en 1962, sans remettre en cause l'internat, envisage de nouvelles modalités d'action : les foyers, l'action éducative en milieu ouvert. En sortant progressivement de l'internat, où il s'est construit, l'éducateur de l'Éducation surveillée va découvrir le jeune dans son milieu, dans sa famille. C'est une nouvelle ère qui s'ouvre pour l'institution, pour l'éducateur, pour le jeune.

Les "vaucressonniens" auront une part importante dans cette évolution. 